\title{
Pioglitazone and alogliptin combination therapy in type 2 diabetes: a pathophysiologically sound treatment
}

This article was published in the following Dove Press journal:

Vascular Health and Risk Management

29 July 2010

Number of times this article has been viewed

\section{Curtis Triplitt \\ Eugenio Cersosimo \\ Ralph A DeFronzo \\ Diabetes Division, Department of Medicine, University of Texas Health Science Center at San Antonio, and the Texas Diabetes Institute, San Antonio, Texas, USA}

Correspondence: Ralph A DeFronzo Diabetes Division, MSC 7886, University of Texas Health Science Center, 7703 Floyd Curl Drive, San Antonio, TX 78229-3900, USA Tel + I 210567669 |

Fax + I 2105676554

Email albarado@uthscsa.edu

\begin{abstract}
Insulin resistance and islet (beta and alpha) cell dysfunction are major pathophysiologic abnormalities in type 2 diabetes mellitus (T2DM). Pioglitazone is a potent insulin sensitizer, improves pancreatic beta cell function and has been shown in several outcome trials to lower the risk of atherosclerotic and cardiovascular events. Glucagon-like peptide-1 deficiency/resistance contributes to islet cell dysfunction by impairing insulin secretion and increasing glucagon secretion. Dipeptidyl peptidase-4 (DPP-4) inhibitors improve pancreatic islet function by augmenting glucose-dependent insulin secretion and decreasing elevated plasma glucagon levels. Alogliptin is a new DPP-4 inhibitor that reduces glycosylated hemoglobin $\left(\mathrm{HbA}_{1 \mathrm{c}}\right)$, is weight neutral, has an excellent safety profile, and can be used in combination with oral agents and insulin. Alogliptin has a low risk of hypoglycemia, and serious adverse events are uncommon. An alogliptin-pioglitazone combination is advantageous because it addresses both insulin resistance and islet dysfunction in T2DM. $\mathrm{HbA}_{1 \mathrm{c}}$ reductions are significantly greater than with either monotherapy. This once-daily oral combination medication does not increase the risk of hypoglycemia, and tolerability and discontinuation rates do not differ significantly from either monotherapy. Importantly, measures of beta cell function and health are improved beyond that observed with either monotherapy, potentially improving durability of $\mathrm{HbA}_{1 \mathrm{c}}$ reduction. The alogliptin-pioglitazone combination represents a pathophysiologically sound treatment of T2DM.
\end{abstract}

Keywords: diabetes, pioglitazone, incretins, DPP-4 inhibitors, alogliptin

\section{Introduction}

The prevalence of type 2 diabetes mellitus (T2DM) has reached epidemic proportions and continues to rise. ${ }^{1}$ Currently, T2DM has been diagnosed in nearly 24 million Americans and is projected to affect nearly 50 million individuals by 2050. Increases in T2DM are paralleled by a robust increase in people at high risk for the development of diabetes. Prediabetes, as of 2007, may be present in up to 57 million individuals through the diagnosis of impaired fasting glucose (100-125 mg/dL) or impaired glucose tolerance (IGT, two-hour value on a $75 \mathrm{~g}$ oral glucose tolerance test [OGTT] of $140-199 \mathrm{mg} / \mathrm{dL}$ ). ${ }^{1}$ It is imperative to understand that development of diabetes is not inevitable with prediabetes. Lifestyle interventions and medications, which will be discussed, may be appropriate in select patients to prevent progression to diabetes. In T2DM, hyperglycemia is the key determinant of microvascular complications, ${ }^{2}$ and the evidence that improving glycemic control lowers the risk of microvascular complications is unequivocal. Hyperglycemia also contributes to macrovascular complications, ${ }^{3}$ although to a lesser extent. As demonstrated in the United Kingdom Prospective Diabetes Study, glycemic control deteriorates progressively over time in T2DM patients treated with sulfonlyureas, 
metformin, and/or insulin. ${ }^{2,4}$ In ADOPT (A Diabetes Outcome Progression Trial), the thiazolidinedione (TZD) rosiglitazone markedly slowed the rise in glycosylated hemoglobin $\left(\mathrm{HbA}_{1 \mathrm{c}}\right)$ in newly diagnosed T2DM patients versus sulfonylureas or metformin, but even monotherapy with the TZD could not completely arrest the deterioration of glycemic control over the five years of follow-up. ${ }^{5}$ Although the progressive worsening of glycemic control can be controlled with lifestyle intervention combined with aggressive stepwise addition of multiple hypoglycemic agents, ${ }^{3,4}$ clinicians often intervene with additional antihyperglycemic agents only when the $\mathrm{HbA}_{1 \mathrm{c}}$ has risen to values that are well above target. ${ }^{6}$ To overcome this problem of clinical inertia and to achieve optimal $\mathrm{HbA}_{1 \mathrm{c}}$ goals, early combination therapy with agents that minimize the risk of hypoglycemia and address the multiple underlying pathophysiologic abnormalities has been advocated to assist clinicians in attaining and maintaining glycemic goals. ${ }^{?}$

In the US, most clinicians initiate therapy with metformin, especially if the patient is overweight. Because metformin improves glucose control, reduces cardiovascular complications in obese patients with T2DM, and is generic, this biguanide represents a logical choice as first-line therapy in diabetic patients. ${ }^{4}$ Addition of a TZD or a sulfonylurea is commonly employed as the next step by most clinicians. Sulfonylureas are generic and inexpensive, but are inferior to metformin and TZDs with respect to durability of $\mathrm{HbA}_{1 \mathrm{c}}$ reduction, ${ }^{5}$ may cause hypoglycemia, and impart no other nonglycemic advantages to the T2DM patient. Most importantly, sulfonylureas, like metformin, do not preserve beta cell function.

The core pathophysiologic disturbances (insulin resistance and impaired insulin secretion) that are present in T2DM can be ameliorated by improving muscle/hepatic insulin sensitivity with the addition of a TZD and correction of glucagon-like peptide-1 (GLP-1) deficiency. GLP-1 agonists (exenatide and liraglutide) and dipeptidyl peptidase-4 (DPP-4) inhibitors (sitagliptin, saxagliptin, vildagliptin, and alogliptin) improve insulin secretion by pancreatic beta cells, and decrease the elevated rate of glucagon secretion by alpha cells. GLP-1 receptors have been identified in the pancreas (beta and alpha cells), kidney, heart, stomach, lung, and brain. ${ }^{8,9}$ GLP-1 enhances glucose-dependent insulin secretion, causes glucose-dependent suppression of elevated glucagon secretion, slows gastric emptying, and reduces food intake. Because the effects of GLP-1 on insulin and glucagon secretion wane as the fasting glucose level returns to normal, hypoglycemia is minimized in T2DM patients treated with GLP-1-based therapy. The glucoregulatory mechanisms by which GLP-1 and exenatide/liraglutide act are similar, but GLP-1 suppresses gastric acid secretion, whereas exenatide and liraglutide do not. ${ }^{10}$ DPP-4 inhibitors augment insulin secretion and inhibit glucagon release, but do not slow gastric emptying and are weight neutral. ${ }^{11}$

Given that approximately $50 \%$ of T2DM patients have $\mathrm{HbA}_{1 \mathrm{c}}$ levels greater than $7 \%$ despite currently available therapies to control glycemia, ${ }^{12-14}$ adverse metabolic effects are often cited as therapeutically limiting by clinicians, and clinical inertia remains a major problem, combination therapy can help to overcome these multiple barriers. In practice, the combination of an insulin sensitizer (metformin or a TZD) with a GLP-1 analog or a DPP-4 inhibitor minimizes the risk of hypoglycemia and weight gain, and can help to achieve and maintain glycemic goals long term. In this review, we briefly examine the pathophysiology of T2DM, with an emphasis on the role of the TZD pioglitazone, incretin analogs, and specifically the DPP-4 inhibitors, with a special emphasis on alogliptin and the combination of pioglitazone-alogliptin.

\section{Abnormal glucose homeostasis in type 2 diabetes}

Insulin resistance and beta cell failure represent the two cornerstone pathophysiologic abnormalities in T2DM. ${ }^{715-19}$ Liver, muscle, and adipose tissue are resistant to the actions of insulin. Basal hepatic glucose production (HGP) is increased despite elevated fasting plasma insulin concentrations, indicating the presence of hepatic insulin resistance. The increase in basal HGP is the primary disturbance responsible for the elevation in fasting plasma glucose (FPG) concentration, and impaired suppression of HGP by insulin contributes to postprandial hyperglycemia. The ability of insulin to increase glucose uptake by peripheral tissues (primarily muscle) is markedly reduced and this peripheral insulin resistance plays a major role in postprandial hyperglycemia. ${ }^{7}{ }^{75}$ Insulin binds to the insulin receptor, resulting in tyrosine phosphorylation both of the insulin receptor and insulin receptor substrate-1 with subsequent activation of phosphoinositol 3 kinase and Akt (Figure 1). Activation of the insulin signaling pathway leads to increased glucose transport into the cell, enhanced glucose phosphorylation (hexokinase II), and stimulation of glycogen synthesis (glycogen synthase) and glucose oxidation (pyruvate dehydrogenase).

The adipocyte is also resistant to insulin, and the accelerated rate of lipolysis contributes to day-long elevation in the plasma free fatty acid (FFA) concentration. ${ }^{20}$ Elevated plasma FFA levels aggravate insulin resistance in both liver and muscle. ${ }^{21}$ FFA metabolites, such as long-chain FACoAs, impair insulin signaling and inhibit glycogen synthesis and glucose oxidation. ${ }^{22}$ In addition, FFAs increase HGP in the liver ${ }^{7,16,23}$ 
A

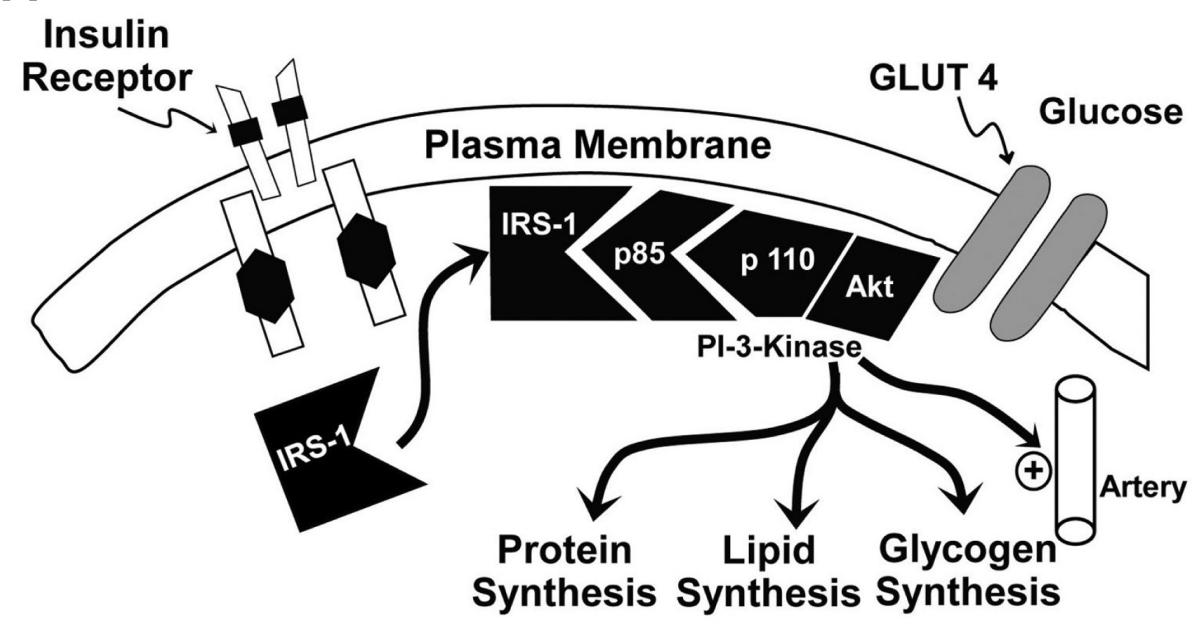

B

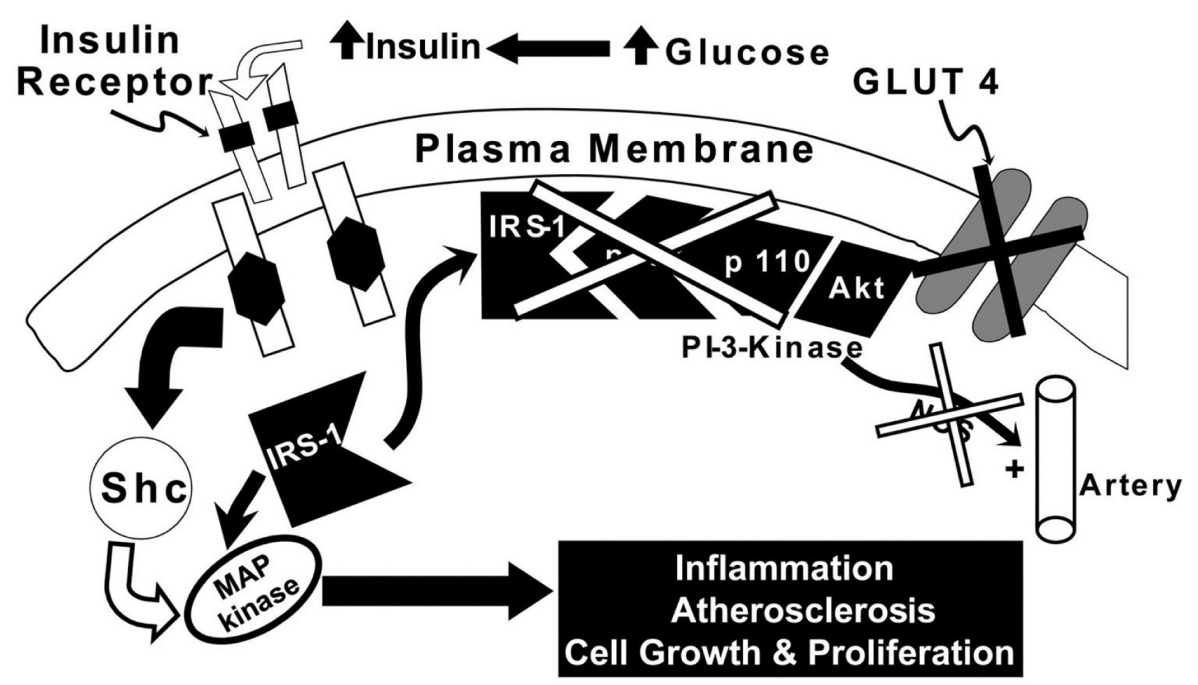

Figure I Insulin signaling system in healthy normal glucose tolerant A) and T2DM B) subjects.

and impair insulin signaling. ${ }^{24}$ Muscle and hepatic insulin resistance, in combination with impaired insulin secretion, are responsible for postprandial hyperglycemia (Figure 2).

Prior to the development of T2DM, the insulin resistance in liver and muscle is compensated by enhanced insulin secretion. ${ }^{7}$ With time, however, pancreatic beta cell function declines (both because of reduced beta cell sensitivity to glucose and decreased beta cell mass) and the plasma glucose concentration rises. Both "glucotoxicity" 25 and "lipotoxicity"26 contribute to the decline in beta cell function. Even small increases in the mean plasma glucose concentration, if present on a chronic basis, can impair insulin secretion by beta cells. ${ }^{27}$ Additionally, elevated plasma FFA concentrations impair insulin secretion and promote beta cell failure. ${ }^{28}$
Beta cell dysfunction can be identified during the OGTT long before the diagnosis of T2DM. At the time of diagnosis of IGT, about $50 \%-60 \%$ of beta cell function has already been lost, while individuals in the upper tertile of IGT (two-hour postprandial glucose 180-199 mg/dL) have lost approximately $70 \%-80 \%$ of their beta cell function. ${ }^{29}$ Thiazolidinediones, ${ }^{30-33}$ exenatide, ${ }^{34,35}$ and possibly the DPP-4 inhibitors, ${ }^{36,37}$ can slow or prevent the decline in beta cell function.

In addition to impaired insulin secretion and moderate to severe insulin resistance, T2DM patients have elevated fasting plasma glucagon levels that fail to suppress normally after a mixed meal and may even rise paradoxically. ${ }^{38-40}$ Evidence for hepatic hypersensitivity to glucagon has also been provided. ${ }^{41}$ The elevated plasma glucagon levels stimulate HGP and con- 


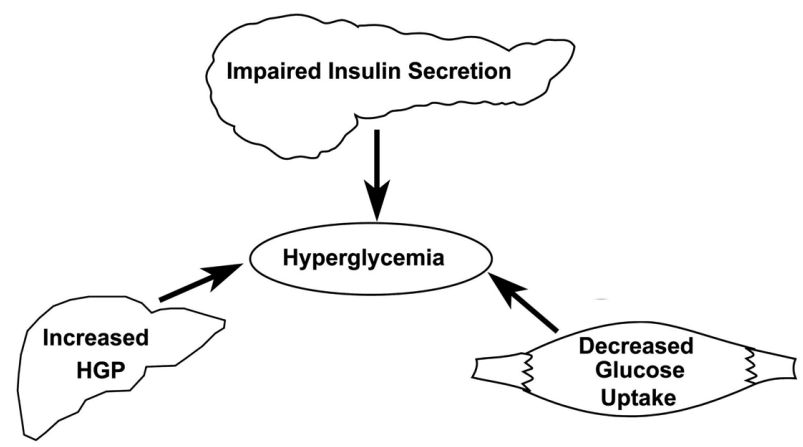

Figure 2 The triumvirate: insulin resistance in liver and muscle with impaired insulin secretion represent the three core defects in T2DM. Reproduced with permission from DeFronzo RA. Lilly lecture. The triumvirate: Beta-cell, muscle, liver. A collusion responsible for NIDDM. Diabetes. 1998;37:667-687. ${ }^{16}$ Copyright (C) 1998 American Diabetes Association.

tribute to fasting and postprandial hyperglycemia. During hyperglycemia, the rate of gastric emptying is normally slowed, resulting in a better match between glucose appearance and glucose disappearance from the circulation. In contrast, patients with newly diagnosed T2DM, despite hyperglycemia, often have an abnormally accelerated gastric emptying rate. ${ }^{42}$ In this review, we first explore the use of pioglitazone for the treatment of T2DM, and then examine therapies designed to augment plasma GLP-1 levels.

\section{Pioglitazone}

\section{Insulin sensitivity and metabolic effects}

Pioglitazone is a potent insulin sensitizer, which binds to the peroxisome-proliferator activated receptor-gamma, resulting in enhanced muscle, liver, and adipose tissue sensitivity to insulin, with a resultant decline in fasting and postprandial plasma glucose levels. ${ }^{43-45}$ Pioglitazone also augments beta cell function ${ }^{46}$ (Figure 3), reduces inflammation, ${ }^{47}$ improves endothelial dysfunction, ${ }^{48,49}$ corrects diabetic dyslipidemia, ${ }^{50}$ and improves the defect in insulin signaling in muscle, leading to impaired glucose transport/metabolism results in increased generation of nitric oxide (NO). NO is a potent vasodilator and antiatherogenic molecule, ${ }^{51,52}$ and deficiency of NO contributes to the markedly increased rate of atherogenesis in T2DM individuals. The compensatory increase in insulin secretion that occurs as the beta cell tries to compensate for the insulin resistance leads to hyperinsulinemia, causing excessive stimulation of the mitogen-activated protein (MAP) kinase pathway which retains normal sensitivity to insulin in T2DM patients. Activation of MAP kinase stimulates multiple intracellular pathways involved in inflammation and augments vascular smooth muscle cell growth and proliferation, thereby promoting atherosclerosis..$^{53}$ TZDs, including pioglitazone, improve insulin signaling and insulin sensitivity in muscle, ${ }^{43,44}$ augment NO generation, and simultaneously inhibit the MAP kinase pathway, thus reducing the risk of atherosclerosis in T2DM (Figure 4).

\section{Hepatic glucose metabolism}

In the liver, pioglitazone increases splanchnic glucose uptake, reduces HGP via inhibition of gluconeogenesis, and decreases hepatic fat content. ${ }^{54}$ Belfort et $\mathrm{al}^{22}$ studied
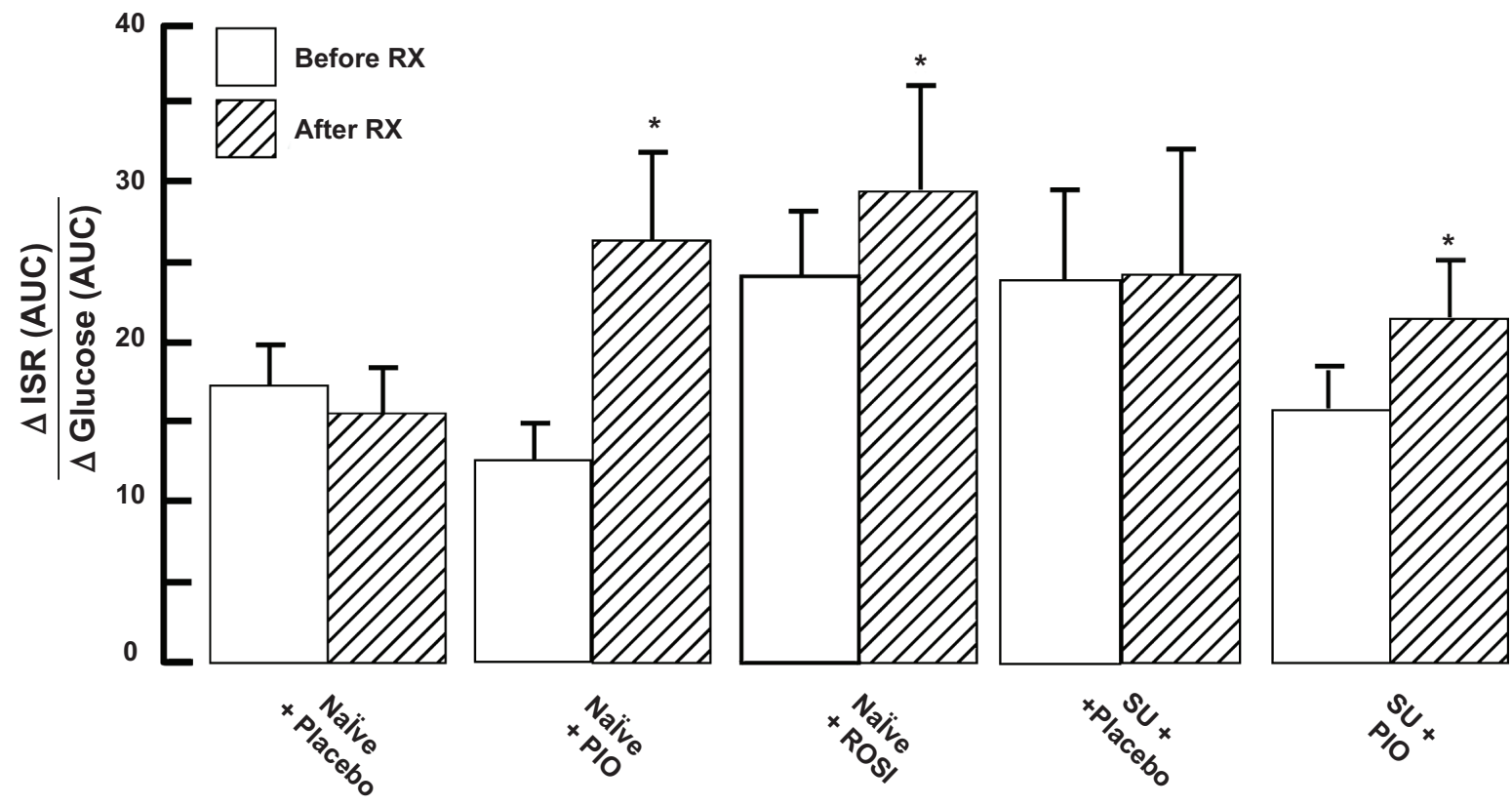

Figure 3 Effect of thiazolidinedione (TZD) treatment on beta cell function

Abbreviations: PIO, pioglitazone; ROSI, rosiglitazone; SU, sulfonylurea; ISR, insulin secretion rate; AUC, area under the curve. 


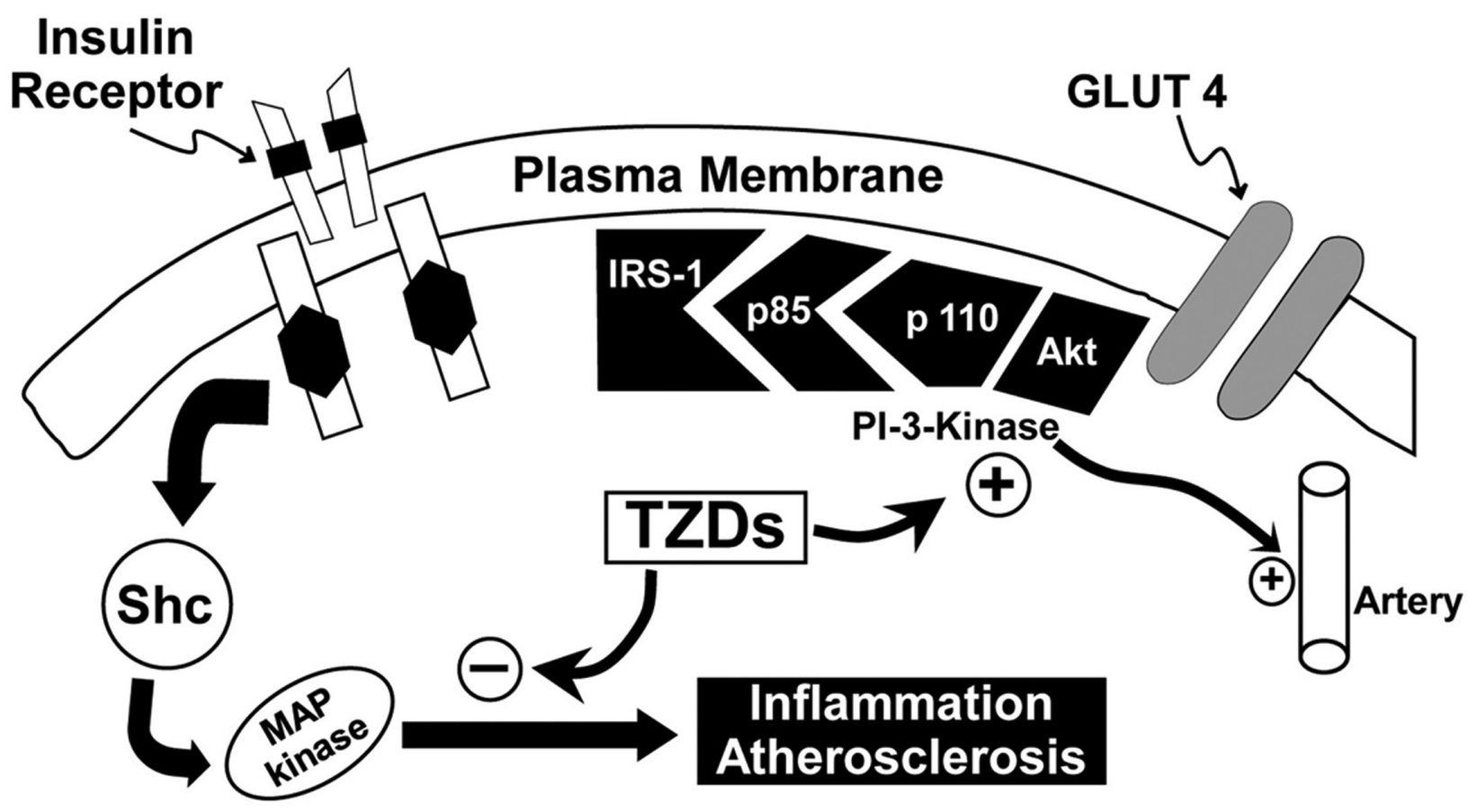

Figure 4 Pioglitazone positively affects the insulin signaling system resulting in improved glycemic control, generation of nitric oxide and decreased MAP kinase pathway activation.

55 subjects with T2DM or IGT and biopsy-confirmed nonalcoholic steatohepatitis. Subjects were randomized to a hypocaloric diet \pm pioglitazone $45 \mathrm{mg} /$ day. After six months of pioglitazone treatment, muscle/hepatic insulin sensitivity improved, liver fat content (measured by magnetic resonance spectroscopy) decreased by $54 \%$, and liver aminotransferase levels were normalized. Liver biopsy demonstrated histologic improvements in steatosis, inflammation, ballooning necrosis, and fibrosis. Pioglitazone also reduced inflammation, as manifested by reductions in C-reactive protein (CRP), tumor necrosis factor alpha, and transforming growth factor-beta, and increased plasma adiponectin levels.

\section{Adipose tissue}

Pioglitazone also exerts positive effects on adipose tissue metabolism. By improving adipocyte sensitivity to the antilipolytic effects of insulin, pioglitazone reduces plasma FFA levels, ${ }^{54,55}$ leading to enhanced insulin sensitivity in muscle/ liver and improved insulin secretion. ${ }^{55-57}$ Pioglitazone also causes a redistribution of fat from highly metabolically active visceral fat (which is associated with accelerated atherogenesis) to subcutaneous fat stores (Figure 5).

\section{Lipids}

Pioglitazone also improves diabetic dyslipidemia, increasing high-density lipoprotein (HDL) cholesterol, reducing plasma triglycerides, and causing a shift from small dense low-density lipoprotein (LDL) to larger more buoyant LDL. Pioglitazone has a neutral effect on LDL cholesterol. In contrast, rosiglitazone increases both LDL and triglyceride levels. ${ }^{50,58}$ Goldberg et al compared the metabolic effects of pioglitazone and rosiglitazone in lipid-lowering agentnaïve subjects over 24 weeks. Pioglitazone significantly increased HDL and lowered triglycerides compared with rosiglitazone. ${ }^{50}$ These differences in plasma lipids may, in part, explain the adverse cardiovascular signal that has been reported with rosiglitazone. ${ }^{59,60}$

\section{Pioglitazone dose-response effect}

Miyazaki et al examined the effect of placebo and pioglitazone $7.5,15,30$, and $45 \mathrm{mg}$ /day daily for 26 weeks in subjects poorly controlled on diet alone. Patients taking previous antidiabetic therapy underwent a 6-8 week washout period. Compared with placebo, $\mathrm{HbA}_{1 \mathrm{c}}$ was significantly reduced in the $15 \mathrm{mg}(-1.3 \%), 30 \mathrm{mg}(-2.0 \%)$, and $45 \mathrm{mg}$ $(-3.0 \%)$ groups versus placebo $(1.2 \%)$. During the OGTT, the insulinogenic index (change in the area under the plasmaconcentration time curve $[\triangle \mathrm{AUC}]$ insulin/ $\triangle \mathrm{AUC}$ glucose) in the $30 \mathrm{mg} /$ day and $45 \mathrm{mg} /$ day groups increased significantly versus placebo. Insulin sensitivity, measured by the Matsuda index of whole-body insulin sensitivity, improved with all doses of pioglitazone, and was greatest at the $45 \mathrm{mg} /$ day dose. The hepatic insulin sensitivity index $(\mathrm{k} / \mathrm{FPG} \times$ fasting plasma insulin) was also significantly improved. ${ }^{61}$ 


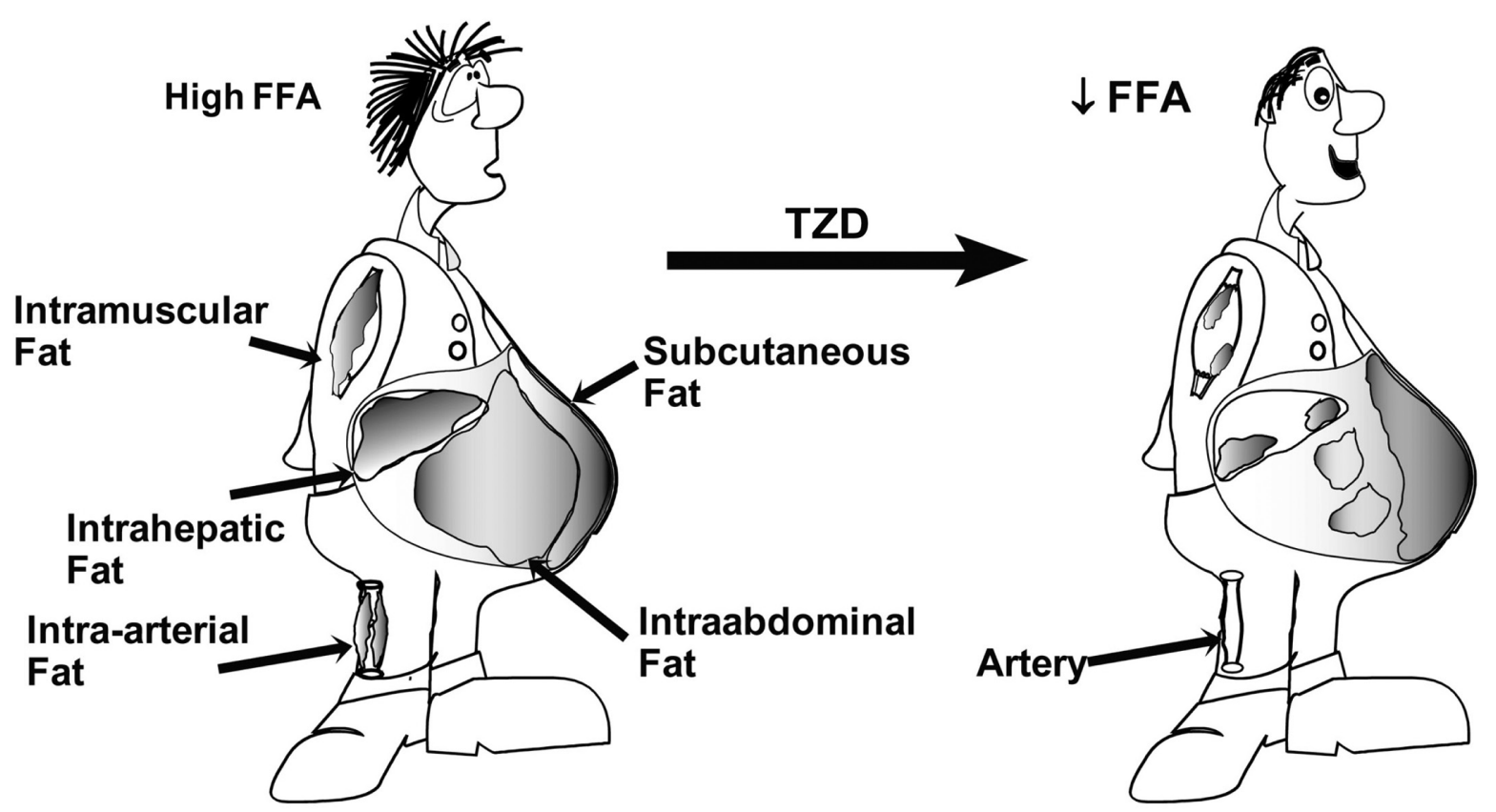

Figure 5 Effect of thiazolidinediones (TZDs) on body fat distribution.

In summary, pioglitazone improves insulin sensitivity in liver, muscle, and adipose tissue, resulting in improvements in glucose and lipid metabolism.

\section{Beta cell effects and impaired glucose tolerance}

TZDs, along with the GLP-1 analogs, are the only classes of drugs that have been shown to enhance and preserve beta cell function. ${ }^{30-33,62-64}$ It is not widely recognized that individuals with IGT are already maximally/near maximally insulin resistant and have lost as much as $70 \%-80 \%$ of their beta cell function. At baseline in the ACT NOW (Actos Now for Prevention of Diabetes) trial (see subsequent discussion) subjects with IGT had a 48\% reduction in insulin sensitivity, as measured by the Matsuda index, and a $78 \%$ reduction in ability of pancreatic beta cells to respond to an oral glucose load versus normal glucose tolerant individuals. ${ }^{65}$ Similar observations have been reported in the VAGES (Veterans Administration Genetic Epidemiology Study) and SAM (San Antonio Metabolism) studies. ${ }^{29,66}$

Buchanan et al first reported on the use of troglitazone $400 \mathrm{mg}$ daily versus placebo in Hispanic women with a previous history of gestational diabetes and IGT. Over a 30-month follow-up period, troglitazone reduced the risk of diabetes by $55 \%$, and this protective effect persisted eight months after discontinuation of troglitazone therapy. ${ }^{31}$ Subjects who completed the study without diabetes were asked to continue in an open-label observational study using pioglitazone $45 \mathrm{mg}$ daily for up to three years. ${ }^{32}$ The annual incidence of diabetes remained low (about 5\%), similar to the rate observed during troglitazone treatment. The best predictor of reduced risk of progression to diabetes was a reduction in early insulin output, as measured by the frequently sampled intravenous glucose tolerance test. Subjects who failed to reduce insulin output during TZD therapy did not have a significant reduction in the risk for T2DM. Thus, "off-loading" the pancreatic beta cells was the best predictor for preventing the progression of IGT to T2DM.

Most recently, pioglitazone has been evaluated in a randomized, double-blind, placebo-controlled trial in 602 subjects confirmed by OGTT to have IGT. Over a mean follow-up of 2.6 years, the risk of progression of IGT to T2DM was reduced by $70 \%(P<0.000001)$. Pioglitazone significantly improved both insulin sensitivity (measured by the Matsuda index and frequently sampled intravenous glucose tolerance test) and pancreatic beta cell function (measured by the insulin secretion/insulin resistance [disposition] index). ${ }^{33}$ In a double-blind, placebo-controlled, four-month study carried out in poorly controlled, drug-naïve, and sulfonylureatreated T2DM patients, both pioglitazone and rosiglitazone significantly improved beta cell function (Figure 3$).{ }^{57} \mathrm{In}$ eight of eight long-term ( $>1.5$ years), double-blind, placebocontrolled or active comparator studies, pioglitazone, as well as rosiglitazone, caused a durable reduction in $\mathrm{HbA}_{1 \mathrm{c}}{ }^{64-73}$ (Figure 6). Such a durable reduction in $\mathrm{HbA}_{1 \mathrm{c}}$ can only be explained by preservation of beta cell function. ${ }^{17}$ 


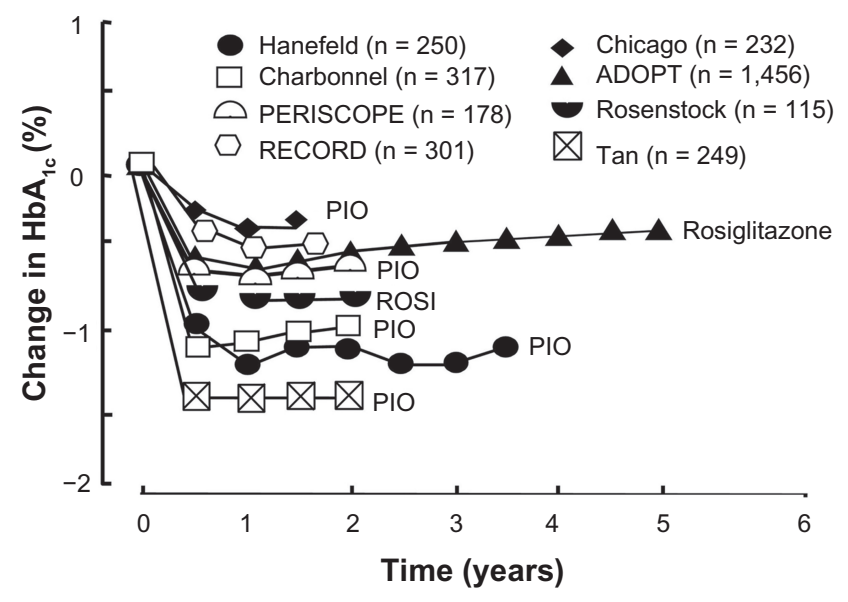

Figure 6 Summary of studies examining the effect of thiazolidinediones (TZDs) versus placebo or versus active-comparator on $\mathrm{HbA}_{\mathrm{IC}}$ in type 2 diabetes subjects. Abbreviations: PIO, pioglitazone; ROSI, rosiglitazone.

\section{Cardiovascular effects}

Both pioglitazone and rosiglitazone improve endothelial dysfunction, decrease high-sensitivity CRP, reduce elevated levels of prothrombotic and inflammatory cytokines, increase plasma adiponectin, and reduce blood pressure. ${ }^{47,74}$ Pioglitazone also lowers plasma triglycerides, raises HDL cholesterol, and converts small dense LDL particles to larger, more buoyant, less atherogenic particles. Both TZDs reduce restenosis after coronary stent placement, and decrease the need for revascularization when given up to six months after stent placement. ${ }^{75}$

Pioglitazone has also been associated with a reduced risk of cardiovascular disease. In a meta-analysis of pioglitazone studies, Lincoff et a $1^{76}$ reported that the combined endpoint of death, myocardial infarction (MI), and stroke was significantly reduced (hazards ratio [HR] 0.82, 95\% confidence interval [CI] 0.72-0.94; $P=0.005]$ ). The PROactive (Prospective Pioglitazone Clinical Trial in Macrovascular Events) trial was designed to explore the cardiovascular benefits of pioglitazone in T2DM subjects at high cardiovascular risk. Entry criteria included history of a prior cardiovascular event. In this double-blind, randomized, placebo-controlled study, eligible subjects were assigned to pioglitazone $45 \mathrm{mg} /$ day or placebo for three years. The primary endpoint (composite of death, MI, stroke, leg amputation, acute coronary syndrome, cardiac bypass, or leg revascularization) was reduced by $10 \%$ but this did not reach statistical significance because of an increase in leg revascularization (HR 0.90, 95\% CI 0.80-1.02; $P=0.095)$. There were 195 events in the pioglitazone group versus 240 in the placebo group. The principal secondary endpoint (Kaplan-Meier time to death, non-fatal MI, or stroke) was reduced by $16 \%$ and did reach statistical significance
(HR 0.84, 95\% CI 0.72-0.98; $P=0.027$ ). ${ }^{77}$ In conclusion, pioglitazone was effective in reducing cerebral and cardiac events, but did not decrease peripheral arterial events. Interestingly, only subjects with baseline peripheral artery disease had an increased risk of leg revascularization (HR 1.68, 95\% CI 1.15-2.47; $P=0.008$ ). Subjects without peripheral artery disease at baseline had no higher risk of leg revascularization. Overall, pioglitazone tended to reduce the primary composite endpoint and significantly reduced the principal secondary endpoint of time to death, MI, and stroke.

In addition to the Lincoff meta-analysis ${ }^{76}$ and PROactive, ${ }^{77}$ two ultrasound studies have provided evidence of anatomic regression of atherosclerotic disease. In the CHICAGO (Carotid Intima-Media Thickness in Atherosclerosis Using Pioglitazone) study, T2DM subjects were randomized to pioglitazone or glimepiride for 18 months and carotid intima-media thickness was measured before and after randomization. In pioglitazone-treated subjects, carotid intima-media thickness did not progress $(-0.001 \mathrm{~mm})$, whereas subjects receiving glimepiride had significant atherosclerosis progression $(+0.012 \mathrm{~mm})$. The absolute difference between treatment groups was $-0.013 \mathrm{~mm}(95 \%$ CI -0.024 to $-0.002 ; P=0.02) .{ }^{69}$

PERISCOPE (Pioglitazone Effect on Regression of Intravascular Sonographic Coronary Obstruction Prospective Evaluation) was a prospective, randomized, double-blind study comparing the effect of 18 months of pioglitazone versus glimepiride on coronary atheroma volume, quantitated with intravascular ultrasound. After 18 months pioglitazone reduced the percentage atheroma volume from baseline $(-0.16 \%)$, whereas glimepiride significantly increased the percentage atheroma volume by $0.73 \%$ (95\% CI $0.33 \%-1.12 \% ; P<0.001)$, resulting in a significant difference between treatment groups $(P=0.002) .{ }^{67}$

\section{Side effects}

Side effects encountered with all TZDs, including pioglitazone, include fat weight gain, fluid retention, and bone fractures. Paradoxically, the greater the fat weight gain, the greater is the decrease in $\mathrm{HbA}_{1 \mathrm{c}}$ and the greater are the increases in insulin sensitivity and beta cell function. ${ }^{78,79}$ Thus, the fat weight gain is purely a cosmetic, not a metabolic, issue. Fluid retention occurs in 5\%-10\% of TZD-treated T2DM patients who are inadequately controlled with sulfonylureas, metformin, and/or insulin and less than $1 \%$ of these individuals develop congestive heart failure (CHF). ${ }^{80,81}$ In PROactive, diabetic subjects who developed CHF on pioglitazone had no increase in mortality, ${ }^{77}$ and in a study by Masoudi et al ${ }^{82}$ TZD-treated 
diabetic individuals who developed CHF had a lower risk of mortality at one-year compared with individuals not treated with an insulin sensitizer. Because of occult diastolic dysfunction in T2DM subjects, fluid overload can lead to $\mathrm{CHF}$. Therefore, pedal edema, an easily detected clinical sign for volume overload, should be treated promptly and aggressively with diuretics (triamterene, spironolactone, amiloride) that work in the collecting duct, ${ }^{83,84}$ and reduction in the pioglitazone dose if necessary to promote diuresis. If the pedal edema does not resolve, pioglitazone should be discontinued. This will minimize the risk of CHF. There is a small increase in the incidence (approximately one per 100 patient treatment years) of bone fractures in postmenopausal diabetic women treated with TZDs. ${ }^{5}$ An increased incidence of fractures has not been seen in premenopausal women or men. The fractures most commonly are related to trauma and involve the distal portions of the long bones of the extremities. To negate the fracture risk completely, one simply could avoid the use of TZDs in postmenopausal women. Alternatively, one could consider obtaining a bone mineralization scan and, if bone density is reduced, avoid the use of TZDs.

Pharmacoeconomic considerations may play a role in the use of pioglitazone in some managed markets, although the previous discussion should clearly delineate TZDs as a unique class of medication for the treatment of T2DM. The cost-effectiveness of pioglitazone, using the CORE (Center for Outcomes Research) diabetes simulation model on the PROactive study data and discounting 3.5\% per annum, was examined. Pioglitazone, using a 35-year time horizon of use, was shown to provide an incremental cost-effectiveness ratio (cost per quality-adjusted life year gained) of $<\$ 50,000$ based on 2005 dollars, which is considered to be cost-effective. ${ }^{85}$

\section{Summary}

In summary, because of the beneficial effects of pioglitazone on insulin sensitivity, beta cell function, durable $\mathrm{HbA}_{1 \mathrm{c}}$ control, and cardiovascular disease, in conjunction with a low risk of hypoglycemia and manageable side effects, we feel that pioglitazone should be considered as first-line therapy in T2DM patients.

\section{Incretinomimetic agents Glucose-dependent insulin secretion and loss of incretin effect}

The incretin effect accounts for approximately $70 \%$ of all insulin that is secreted during an OGTT in normal glucose tolerant subjects ${ }^{86}$ and GLP-1 and glucose-dependent insulinotrophic polypeptide (previously called gastric inhibitory polypeptide, GIP) account for over $90 \%$ of the incretin effect. GLP-1 is secreted from the L-cells in the distal small intestine/colon in response to mixed meals (glucose or fat). Circulating concentrations of GLP-1 rise rapidly within minutes after food ingestion indicating that neural signals, initiated by food entry in the proximal gastrointestinal tract, stimulate GLP-1 secretion via the L-cells. ${ }^{87}$ Acutely, GLP-1 promotes normal glucose homeostasis by augmenting insulin secretion, inhibiting glucagon secretion and delaying gastric emptying.

GIP is secreted by the K-cells of the early small intestine in response to meal ingestion. However, unlike GLP-1, GIP does not inhibit glucagon secretion, does not slow gastric emptying, inhibit food intake, or promote weight loss. ${ }^{88}$ Both GLP-1 and GIP are rapid degraded by the DPP-4, which is ubiquitously present in plasma and on all cell membranes. Thus, the secreted GLP-1 and GIP have a short half-life in the range of 2-3 minutes.

As individuals progress from normal glucose tolerance to IGT to T2DM, stimulated GLP-1 levels decline ${ }^{89,90}$ (Figure 7), and there is beta cell resistance to the glucose-dependent stimulatory effect of both GLP-1 and GIP on insulin secretion. ${ }^{91}$ In T2DM the contribution of incretin hormones to the insulin response has been estimated to be reduced to about $36 \%$ in T2DM subjects. ${ }^{86,92}$ From the therapeutic standpoint, one can increase circulating GLP-1 levels by administering a GLP-1 analog that is resistant to DPP-4 degradation or by giving a DPP-4 inhibitor. ${ }^{793,94}$

The insulinotropic action of GLP-1 is glucose-dependent. In order for GLP-1 to enhance insulin secretion, the plasma glucose concentration must be higher than $90 \mathrm{mg} / \mathrm{dL} .{ }^{95-99} \mathrm{In}$ contrast, sulfonylureas stimulate insulin secretion irrespective of the ambient glucose concentration. Clinically, this results in an elevated risk of hypoglycemia with sulfonylureas. GLP-1 does not produce significant hypoglycemia. In addition to its stimulatory effect on insulin secretion, GLP-1 augments insulin biosynthesis and gene transcription, thereby restoring the cellular supplies of insulin for subsequent release. ${ }^{100-103}$ Of great interest, studies in animals have shown that GLP-1 stimulates islet neogenesis, causes beta cell replication, and inhibits beta cell apoptosis, leading to an increase in beta cell mass. ${ }^{104}$ However, short-term washout studies with exenatide suggest that exenatide is unlikely to increase beta cell mass in humans. ${ }^{64}$

\section{Elevated plasma glucagon levels}

For over 30 years, it has been known that fasting plasma glucagon levels are increased in T2DM and that gluca- 
A

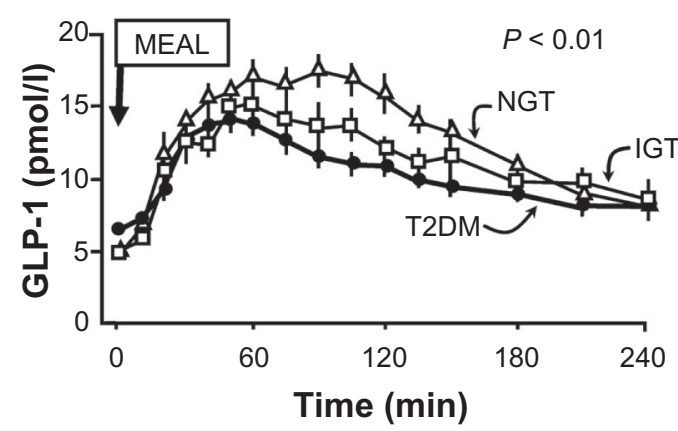

B

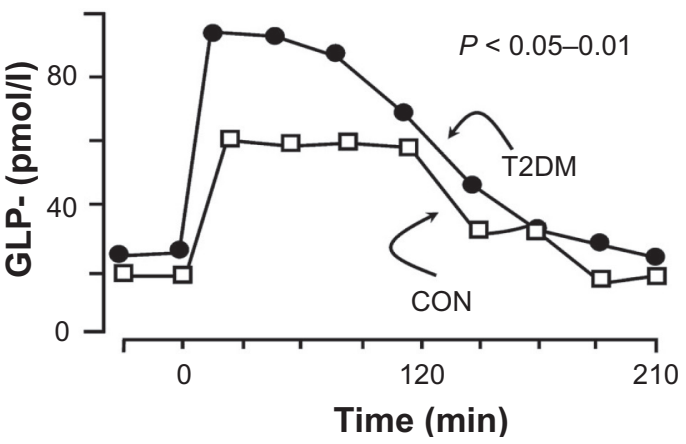

Figure 7 GLP-I levels decline as glucose tolerance deteriorates A), whereas GIP levels are normal or elevated in patients with type 2 diabetes mellitus B). ${ }^{86-88}$

gon secretion is not appropriately suppressed following a carbohydrate or mixed meal or may paradoxically increase. ${ }^{105-107}$ This abnormality is evident before the diagnosis of diabetes, and has been observed in subjects with IGT. ${ }^{108-110}$ Hyperglucagonemia in the fasting state results in excessive HGP and elevated FPG levels, while impaired suppression of plasma glucagon levels following a meal results in postprandial hyperglycemia. The main physiologic role of glucagon is to oppose the action of insulin on HGP in order to protect against hypoglycemia and restore normoglycemia. ${ }^{111}$ GLP-1 inhibits the inappropriately high glucagon secretion after a meal, both directly through the GLP-1 receptor on the alpha cell and indirectly by stimulating insulin secretion, although the absolute contribution of each component is still debated. ${ }^{12}$ This glucose-dependent inhibitory effect of GLP-1 on glucagon secretion reduces HGP and decreases postprandial plasma glucose levels. ${ }^{113}$

\section{Correction of accelerated gastric emptying}

The rate of gastric emptying is a key determinant of postprandial glucose excursion. ${ }^{14-116}$ Mismatch between the rate of glucose appearance in the systemic circulation and the rate of glucose disappearance can account for as much as $34 \%$ of the variability in peak postprandial glucose concentrations following glucose ingestion in normal glucose tolerant subjects. ${ }^{14,117,118}$ The normal physiologic response to hypoglycemia is to accelerate gastric emptying. This increases nutrient delivery into the systemic circulation and restores normal plasma glucose concentrations. During hyperglycemia, the rate of gastric emptying is slowed, resulting in a better match between glucose appearance and glucose disappearance from the circulation. Despite hyperglycemia, newly diagnosed T2DM patients often have an accelerated rate of gastric emptying that can exceed the rate of gastric emptying in NGT subjects by $25 \%-30 \%{ }^{116-119}$

GLP-1, which is deficient and to which the beta cell is resistant in T2DM, is a potent inhibitor of gastric emptying, and slows the rate of glucose appearance in the systemic circulation. ${ }^{86}$ GLP-1 agonists, such as exenatide, delay gastric emptying in healthy, nondiabetic subjects ${ }^{93}$ and in individuals with T2DM. ${ }^{113,120}$ The effect of GLP-1 and exenatide on inhibition of gastric emptying is centrally mediated by vagal afferent nerves. ${ }^{121}$

\section{Reduction in food intake}

GLP-1 administration reduces food intake and body weight in a dose-dependent manner. In animal models, the inhibitory effect on food intake is observed when GLP-1 is administered peripherally $^{122}$ or intraventricularly. ${ }^{123,124}$ The inhibition of food intake by GLP-1 results from activation of GLP-1 receptors in the hypothalamus and the area postrema, which are accessible from the systemic circulation. ${ }^{125}$ A meta-analysis of seven human studies has demonstrated that GLP-1 administration reduces energy intake and increases satiety in lean and overweight subjects. ${ }^{126}$

\section{Incretin formulations}

Because the half-life of GLP-1 is extremely short (less than minutes), it is not practical for use in the treatment of T2DM patients. To overcome the rapid degradation of GLP-1 by DPP-4, ${ }^{127}$ two approaches have been developed, ie, alteration of the peptide structure of GLP-1 to prevent its degradation by DPP-4, but allow GLP-1 receptor activation, and development of DPP-4 inhibitors, which block the degradation of GLP-1 by DPP-4, thus increasing the reduced concentrations of GLP-1 back to normal physiologic levels in T2DM.

In a mechanism of action study, DeFronzo et $\mathrm{al}^{10}$ compared sitagliptin, a DPP-4 inhibitor, with exenatide, a GLP-1 agonist. T2DM subjects on a stable dose of metformin were randomized 
to sitagliptin $100 \mathrm{mg}$ daily for two weeks or exenatide $5 \mu \mathrm{g}$ bid for one week, then $10 \mu \mathrm{g}$ bid for one week. Subjects were crossed over after two weeks and followed for an additional two weeks. At baseline and at the end of each two-week period, subjects received a meal tolerance test with acetaminophen to measure gastric emptying. After the initial two weeks of treatment, the mean plasma glucose concentration and the two-hour post-meal plasma glucose concentration were markedly reduced in the exenatide versus sitagliptin groups (133 versus $208 \mathrm{mg}$ / $\mathrm{dL}, P<0.001)$. The greater reduction in postprandial glucose excursion with exenatide was accounted for by a higher insulinogenic index, a greater inhibition of glucagon secretion, and delayed gastric emptying. Sitagliptin had no effect on gastric emptying, but did reduce plasma glucagon levels. The greater reduction in FPG and plasma glucagon concentrations and the greater increase in insulin secretion in the exenatide-treated group was explained by the pharmacologic exenatide levels achieved (64 pM) compared with the more physiologic GLP-1 concentrations (15 pM) achieved with sitagliptin. ${ }^{10}$

\section{Alogliptin}

Alogliptin benzoate (formerly called SYR-322) is a noncovalent, selective inhibitor of DPP-4. ${ }^{28}$ Active GLP-1 is rapidly converted to inactive GLP-1 (9-36 amide or 9-37 amide) by the serine protease DPP-4. Alogliptin prevents the degradation of endogenous GLP-1 (and GIP), thus extending its half-life and restoring endogenous GLP-1 to normal physiologic levels.

\section{Animal data}

Rats with streptozotocin-induced diabetes and maintained on glibenclamide $10 \mathrm{mg} / \mathrm{kg}$ per day for 27 days were divided into four groups at 20 weeks of age and treated with placebo, glibenclamide $10 \mathrm{mg} / \mathrm{kg} /$ day, nateglinide $50 \mathrm{mg} / \mathrm{kg} /$ day, or alogliptin $1 \mathrm{mg} / \mathrm{kg}$ /day prior to an oral glucose load (1 mg/kg). Alogliptin significantly increased the plasma insulin concentration at 10 minutes and decreased the glucose AUC from 0-120 minute glucose compared with rats receiving glibenclamide and nateglinide prior to the oral glucose load. In a separate group of diabetic rats, DPP-4 activity and plasma GLP-1 levels (GLP-1 [7-36 amide] and GLP-1 [7-37 amide]) were inversely related to the dose of alogliptin over the range $0.03-3.0 \mathrm{mg} / \mathrm{kg} .{ }^{129}$

Pertinent to the use of combined alogliptin-pioglitazone therapy, seven-week-old male $L e p^{o b} / L e p^{o b}(o b / o b)$ mice and their nondiabetic male littermates received placebo, alogliptin $45.7 \mathrm{mg} / \mathrm{kg} /$ day, pioglitazone $4.0 \mathrm{mg} / \mathrm{kg} /$ day, or both (alogliptin-pioglitazone) for 33 days. In mice treated with alogliptin, plasma DPP-4 activity was inhibited by $80 \%$, and plasma active GLP-1 levels were increased 3.5-fold and 4.1fold in the alogliptin alone and alogliptin-pioglitazone groups, without a change in the pioglitazone alone group. Insulin levels were increased approximately 1.5 -fold in alogliptin- and pioglitazone-treated mice, and 3.2-fold in alogliptin-pioglitazone mice. Glucagon levels were decreased by approximately $25 \%$ in alogliptin-treated and alogliptin-pioglitazone treated mice, whereas no change was seen in the pioglitazone or placebo groups. Adiponectin increased only in mice who received pioglitazone. $\mathrm{HbA}_{1 \mathrm{c}}$ levels decreased by 1.0, 1.5, and 2.3 in the alogliptin-, pioglitazone- and alogliptin-pioglitazone-treated mice, respectively. Pancreatic insulin content increased by 1.3-, 1.5-, and 2.2-fold in mice treated with alogliptin, pioglitazone, and alogliptin-pioglitazone, respectively. In conclusion, the addition of alogliptin to pioglitazone produced completely additive metabolic and hormonal effects in $o b / o b$ mice. ${ }^{130}$

\section{Human data}

\section{Pharmacokinetic and pharmacodynamic profile}

Healthy males $(n=36)$ received a single dose of alogliptin (five subjects for each dose at 25, 50, 100, 200, 400, or $800 \mathrm{mg}$ ) or placebo (one subject per each dosing cohort) 30 minutes prior breakfast, and pharmacokinetic and pharmacodynamic parameters were measured over the next 24 hours. Alogliptin was rapidly absorbed and reached maximal concentrations in approximately two hours. Over the dosing range, the rise in plasma alogliptin concentration was linear, and the $t_{1 / 2}$ was approximately 16-20 hours after the single dose. In these normal healthy subjects, plasma GLP-1 levels increased 2.5- to 4.0-fold versus placebo over the 24-hour period, with the highest levels achieved 60-120 minutes after ingestion of the meal. ${ }^{131}$

In a second randomized, double-blind, placebo-controlled study, diet-treated T2DM subjects received alogliptin 25, 100, or $400 \mathrm{mg}$ daily for 14 days. Alogliptin was rapidly absorbed, with a time to maximal concentration of about one hour. At 14 days, the half-life was consistent at approximately 20 hours, supporting daily dosing of alogliptin. Most of the alogliptin (nearly 60\%) was recovered unchanged in the urine after 24 hours. The data suggest that alogliptin undergoes some renal secretion, and, similar to other marketed DPP-4 inhibitors, requires a dose reduction in patients with moderate to severe renal impairment. ${ }^{132,133}$ One active metabolite (N-demethylated alogliptin), which is as active as the parent compound, was identified, but it accounted for only $1 \%$ of the recovered drug. After 14 days, all three doses of alogliptin inhibited plasma DPP-4 by more than $80 \%$ at 24 hours. Consistent with other DPP-4 inhibitors, alogliptin reduced postprandial plasma 
glucose levels, but plasma insulin levels did not change significantly. However, the increment in insulin per increment in glucose clearly increased, indicating an effect on the beta cells to augment insulin secretion. Glucagon levels were not measured but, in previously reported animal studies, plasma glucagon was reduced by $25 \% .{ }^{128,134}$

\section{Clinical studies}

Alogliptin has been studied in T2DM subjects as monotherapy and in combination with metformin, sulfonylureas, pioglitazone, and insulin (see Figure 8). DeFronzo et $\mathrm{al}^{135}$ in a randomized, double-blind, placebo-controlled trial, reported on drug-naïve, poorly controlled $\left(\mathrm{HbA}_{1 \mathrm{c}} 7.9 \% \pm 0.8 \%\right) \mathrm{T} 2 \mathrm{DM}$ patients $(\mathrm{n}=329)$ treated with alogliptin 12.5 and $25 \mathrm{mg}$ /day or placebo for 26 weeks. Baseline characteristics were similar (Table 1) in all three groups. Alogliptin $12.5 \mathrm{mg} /$ day $(-0.56 \%$ and $-10 \pm 4 \mathrm{mg} / \mathrm{dL} ; P<0.001$ for both) and $25 \mathrm{mg} /$ day $(-0.59 \%$ and $-16 \pm 4 \mathrm{mg} / \mathrm{dL} ; P<0.001$ for both) similarly reduced $\mathrm{HbA}_{1 \mathrm{c}}$ and FPG compared with placebo $(-0.02 \%$ and $+11 \pm 5 \mathrm{mg} / \mathrm{dL}$ ). More subjects were able to achieve an $\mathrm{HbA}_{1 \mathrm{c}} \leq 7.0 \%$ with alogliptin $12.5 \mathrm{mg} /$ day $(47.4 \% ; P=0.001)$ or $25 \mathrm{mg} /$ day $(44.3 \% ; P=0.008)$ versus placebo $(23.4 \%)$. Approximately $50 \%$ of subjects on either dose of alogliptin had at least $\mathrm{a} \geq 0.5 \% \mathrm{HbA}_{1 \mathrm{c}}$ reduction, and about $29 \%$ had a $\geq 1.0 \%$ reduction in $\mathrm{HbA}_{1 \mathrm{c}}$. Alogliptin was weight neutral and, at both doses, improved the proinsulin-to-insulin ratio. Alogliptin
$25 \mathrm{mg} /$ day resulted in a small, but significant reduction in plasma total cholesterol and triglyceride concentration.

In a double-blind, randomized, placebo-controlled 26-week trial, Pratley et al ${ }^{136}$ compared alogliptin 12.5 and $25 \mathrm{mg} /$ day versus placebo in 500 poorly controlled (mean $\mathrm{HbA}_{1 \mathrm{c}} 8.1 \%$ ) T2DM subjects taking background sulfonylurea therapy. Subjects were required to be on sulfonylurea monotherapy for at least three months prior to screening and had to be without serious concomitant diabetic complications. Subjects were switched to glyburide at equivalent dose, if necessary, and completed a four-week glyburide run-in period (Table 1). $\mathrm{HbA}_{1 \mathrm{c}}$ was reduced in the alogliptin $12.5 \mathrm{mg} /$ day $(-0.39 \%)$ and $25 \mathrm{mg} /$ day $(-0.53 \%)$ groups versus placebo $(+0.1 \%$; both $P<0.001)$. As with other antihyperglycemic agents, the $\mathrm{HbA}_{1 \mathrm{c}}$ reduction was correlated positively with baseline $\mathrm{HbA}_{1 \mathrm{c}}$. In subjects with a baseline $\mathrm{HbA}_{1 \mathrm{c}} \geq 9.0 \%$, the $\mathrm{HbA}_{1 \mathrm{c}}$ reduction with alogliptin $12.5 \mathrm{mg} /$ day $(-0.82 \%)$ and $25 \mathrm{mg} /$ day $(-1.06 \%)$ were more robust. Weight increased slightly $(0.6 \mathrm{~kg})$ over the 26 -week study, and there were no significant lipid changes.

In a randomized, double-blind, placebo-controlled trial of 26 weeks, Nauck et a $1^{137}$ treated poorly controlled T2DM with alogliptin $12.5 \mathrm{mg} /$ day $(\mathrm{n}=213), 25 \mathrm{mg} /$ day $(n=210)$, or placebo $(n=104)$. Prior to randomization, all subjects entered a four-week run-in period on a stable dose of metformin $\geq 1500 \mathrm{mg} /$ day ( mean dose $=1847 \mathrm{mg} /$ day). Subjects could not have significant diabetes-related complica-

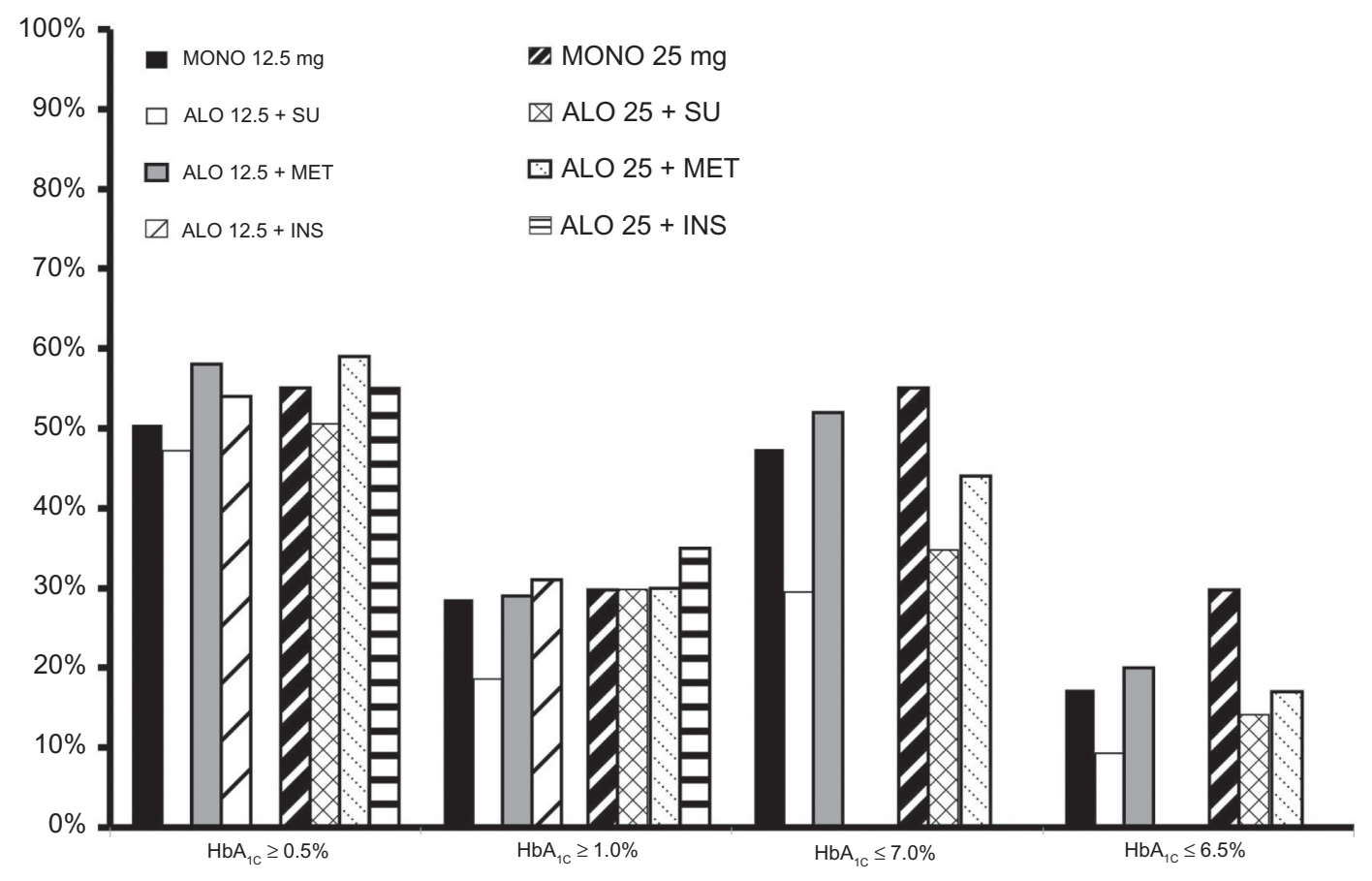

Figure 8 Percentage (\%) of subjects achieving select $\mathrm{HbA}_{1 \mathrm{c}}$ targets with alogliptin in Phase 3 trials. ${ }^{135-138}$ Abbreviations: ALO, alogliptin; SU, sulfonylurea; MET, metformin; INS, insulin; MONO, monotherapy with alogliptin. 


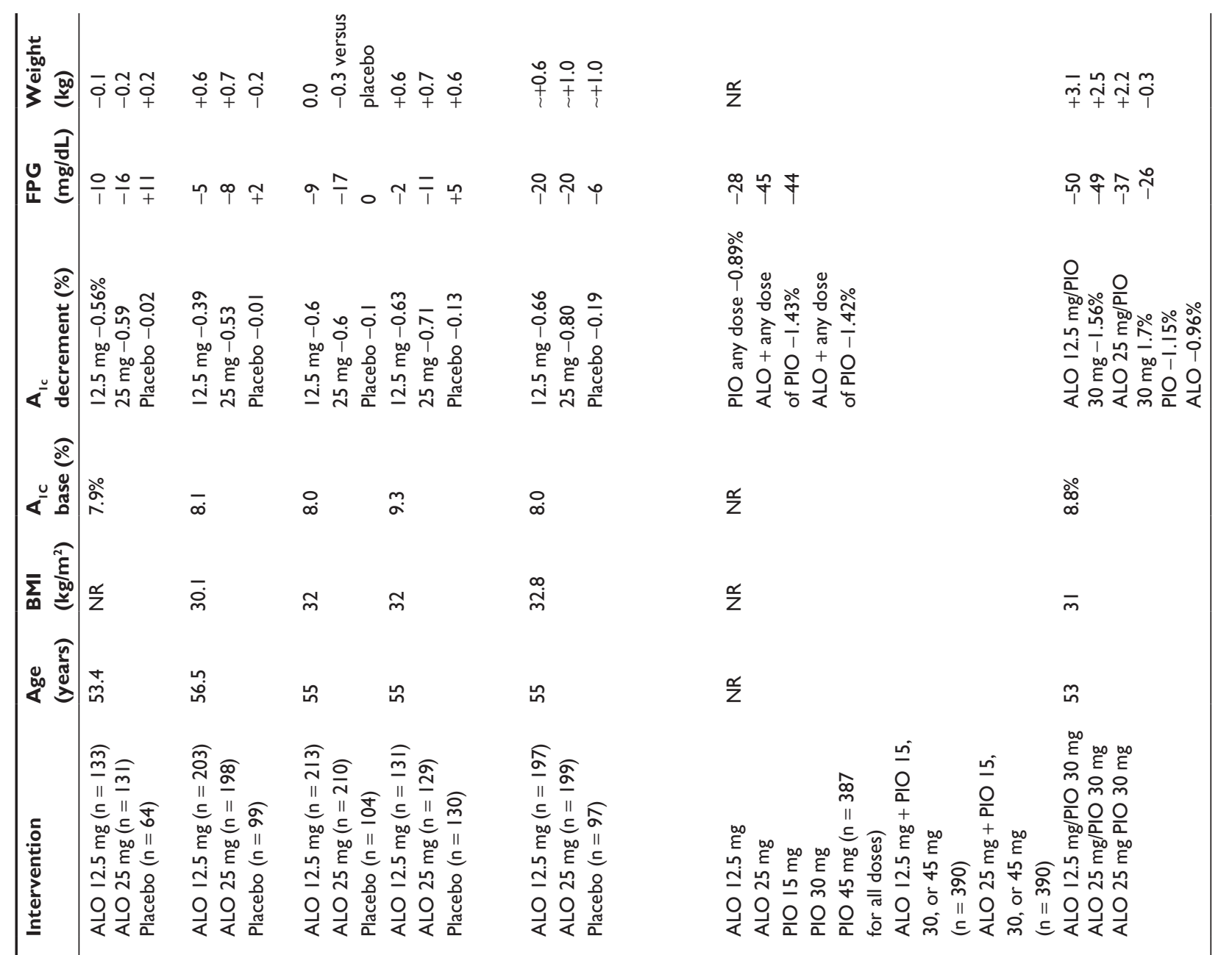
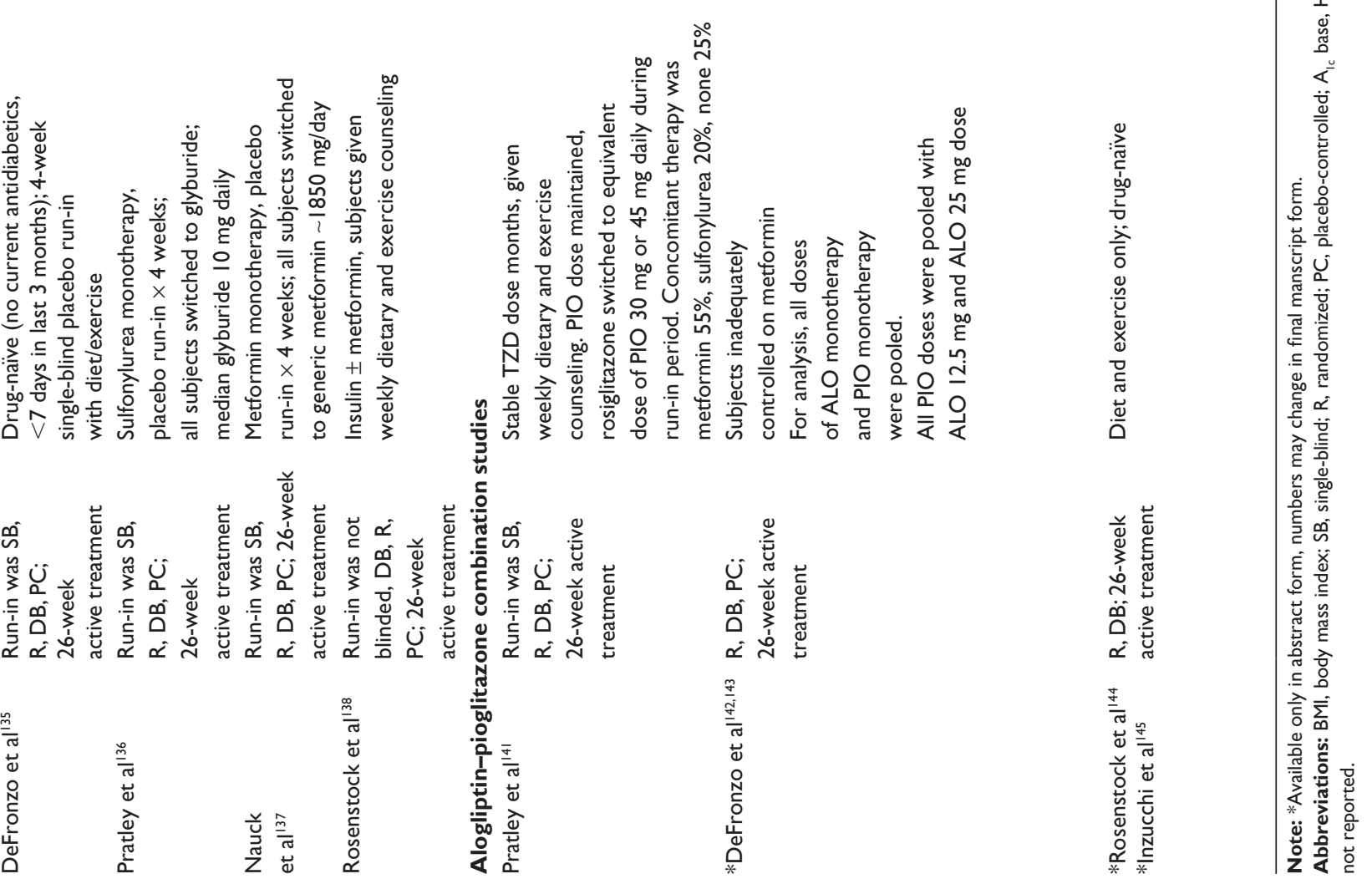
tions. At baseline, all three groups were well matched, with an $\mathrm{HbA}_{1 \mathrm{c}}$ of $7.9 \%-8.0 \%$ and FPG of $168-180 \mathrm{mg} / \mathrm{dL} . \mathrm{HbA}_{1 \mathrm{c}}$ was significantly reduced by $-0.6 \%$ on the 12.5 and $25 \mathrm{mg}$ /day alogliptin doses versus placebo $(-0.1 \%)$. The reduction from baseline in FPG was greater in the alogliptin $12.5 \mathrm{mg} /$ day $(-19 \mathrm{mg} / \mathrm{dL})$ and $25 \mathrm{mg} /$ day $(-17 \mathrm{mg} / \mathrm{dL})$ groups versus placebo (no change; both $P<0.001$, Table 1).

Rosenstock et $\mathrm{al}^{138}$ explored the addition of alogliptin 12.5 and $25 \mathrm{mg} /$ day versus placebo in T2DM subjects inadequately controlled on insulin (at least $15 \mathrm{U} /$ day but not more than $100 \mathrm{U} /$ day) \pm metformin therapy in a 26-week, randomized, double-blind, placebo-controlled trial. Subjects were not allowed to have significant diabetes-related complications. The groups were well matched at baseline, with a mean $\mathrm{HbA}_{1 \mathrm{c}}$ of $9.3 \%$, FPG about $190 \mathrm{mg} / \mathrm{dL}$, and diabetes duration of 12-13 years. At baseline all subjects were on insulin $(64 \%$, premix or insulin "combo"; $34 \%$, long-acting insulin; $2 \%$, short-acting insulin), and $60 \%$ of subjects were taking metformin (mean dose $>1500 \mathrm{mg}$ daily). After 26 weeks, alogliptin 12.5 and $25 \mathrm{mg}$ /day significantly reduced $\mathrm{HbA}_{1 \mathrm{c}}(-0.63 \%$ and $-0.71 \%$, respectively) compared with placebo (0.13\%). Only alogliptin $25 \mathrm{mg} /$ day significantly reduced FPG $(-11 \mathrm{mg} / \mathrm{dL} ; P=0.03)$. Insulin doses were fairly stable throughout the 26-week study. Weight changes were similar in the placebo and alogliptin groups, and no significant changes in the lipid profile were noted (Table 1).

In all four of these trials, ${ }^{135-138}$ the reduction in $\mathrm{HbA}_{1 \mathrm{c}}$ was $0.5-1.0 \%$ on mean (Figure 8 ). All four trials provided information on the number of subjects who required rescue therapy. For alogliptin in combination with metformin or glyburide, or as monotherapy, rescue therapy guidelines were $\mathrm{FPG} \geq 275 \mathrm{mg} / \mathrm{dL}$ after more than one week of treatment, $\geq 250 \mathrm{mg} / \mathrm{dL}$ after week 4 , and $\geq 225 \mathrm{mg} / \mathrm{dL}$ after week 8 , or $\mathrm{HbA}_{1 \mathrm{c}} \geq 8.5 \%$ with a $\leq 0.5 \%$ reduction from baseline by week $12 .{ }^{135-137}$ In the Rosenstock et al ${ }^{138}$ paper, the rescue criteria were $\mathrm{FPG} \geq 300 \mathrm{mg} / \mathrm{dL}$ after more than one week of treatment, $\geq 275 \mathrm{mg} / \mathrm{dL}$ after week 4 , and $\geq 250 \mathrm{mg} / \mathrm{dL}$ after week 8 , or $\mathrm{HbA}_{1 \mathrm{c}} \geq 8.7 \%$ with a $\leq 0.5 \%$ reduction from baseline by week 12 (Figure 9 ). The combination of metformin with alogliptin required fewer hyperglycemic rescues, although no statistical analysis was done on the differences.

\section{Adverse events and tolerability in Phase III trials}

DPP-4 inhibitors, including alogliptin, are very well tolerated. ${ }^{135-138}$ The incidence of all adverse events was,

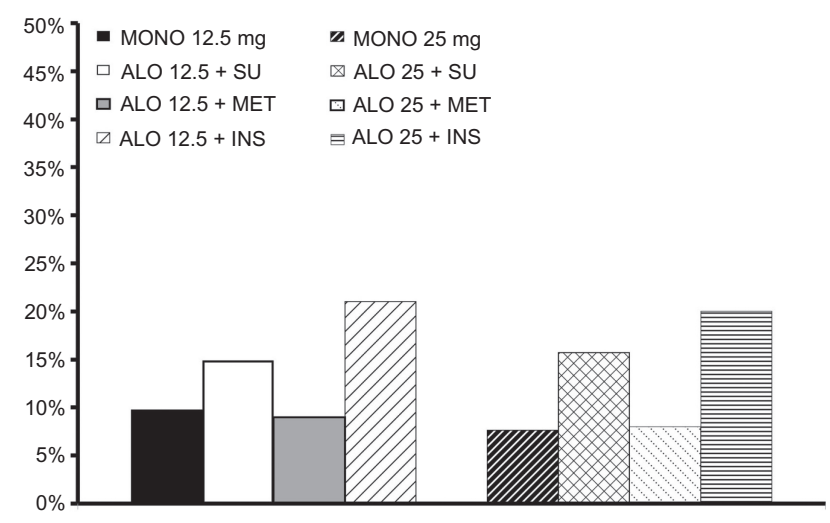

Figure 9 Necessity for hyperglycemic rescue* in Phase III trials with alogliptin..$^{135-138}$ *see text for definitions

Abbreviations: ALO, alogliptin; SU, sulfonylurea; MET, metformin; INS, insulin; MONO, monotherapy with alogliptin.

in general, similar to placebo, and not dose-dependent. Discontinuation rates were not different from placebo in any of the studies. The most common adverse events reported across studies were upper respiratory infection, urinary tract infection, nasopharyngitis, headache, diarrhea, arthralgia, and peripheral edema. Headache occurred more frequently than placebo in one study. ${ }^{135}$ Alogliptin monotherapy had slightly higher gastrointestinal events (abdominal pain, nausea, diarrhea, and vomiting) versus placebo. Other adverse effects of special interest were skin lesions and pruritus, which were closely monitored. Skin lesions were very rare. With alogliptin monotherapy, at $25 \mathrm{mg} /$ day, one case of subcorneal pustular dermatosis was reported. There were no cases of skin lesions with glyburide-alogliptin. ${ }^{136}$ In the metformin-alogliptin study, skin lesions were observed in $7.7 \%$ of placebo versus $12 \%$ of alogliptin-treated subjects. ${ }^{137}$ In the insulin \pm metformin study, skin lesions occurred in about $12 \%$ of alogliptin-treated patients versus $10.9 \%$ of patients receiving placebo. ${ }^{138}$ Pruritus occurred slightly more frequently with alogliptin. The severity of side effects was mild to moderate, and serious adverse events were not common and did not occur more frequently than placebo. Serious adverse events potentially related to alogliptin included one subject with cholecystitis and pancreatitis, one with $\mathrm{CHF}$, one with pulmonary embolism, and one with severe hypoglycemia when alogliptin was combined with glyburide. ${ }^{135-138}$

Hypoglycemia rates were dependent upon concomitant therapy. In monotherapy, hypoglycemia rates were $1.5 \%-3.0 \%$ and similar to placebo. ${ }^{135}$ When alogliptin was combined with metformin, hypoglycemia occurred in 3\% of the placebo group, $1 \%$ of the alogliptin $12.5 \mathrm{mg} /$ day group, and in none of the subjects in the alogliptin $25 \mathrm{mg} /$ day group. ${ }^{137}$ Hypoglycemia was defined as $<60 \mathrm{mg} / \mathrm{dL}$ with symptoms or $<50 \mathrm{mg} / \mathrm{dL}$ 
with or without symptoms. These clinical observations reinforce the mechanism of action of endogenously-secreted GLP-1 on insulin secretion as being glucose-dependent and demonstrate that, when the DPP-4 inhibitor alogliptin is administered with agents that do not augment insulin secretion, hypoglycemia is uncommon and does not occur more frequently than in the placebo group. Rates of hypoglycemia when alogliptin was combined with glyburide were $11.1 \%$ in the placebo group, $15.8 \%$ in the alogliptin $12.5 \mathrm{mg} /$ day group, and $9.6 \%$ in the alogliptin $25 \mathrm{mg} /$ day group. ${ }^{136}$ When combined with insulin, 24\%, 26.7\%, and $27.1 \%$ experienced hypoglycemia in the placebo, alogliptin $12.5 \mathrm{mg} /$ day, and alogliptin $25 \mathrm{mg} /$ day groups, respectively. ${ }^{138}$ As expected, the rates of hypoglycemia were higher in insulin-treated T2DM patients, but alogliptin did not significantly exacerbate the risk of hypoglycemia.

\section{Alogliptin selectivity}

Selectivity of alogliptin for DPP-4 inhibition is defined as a $>10,000$ greater affinity for the DPP-4 enzyme than for competing DPP enzymes, such as DPP-2, 8, and 9. Activation of DPP-8 and DPP-9 have been associated with untoward side effects, including thrombocytopenia, anemia, splenic enlargement, alopecia, and skin lesions. Therefore, selectivity for DPP-4 is desirable. DPP-4 inhibition can also prolong the action of endogenous peptides, such as pituitary adenylate cyclase-activating peptide, growth hormone-releasing hormone, peptide YY, neuropeptide Y, and substance P, as well as several other chemokines. However, to date, alogliptin has not been reported to cause an increase in side effects that may be related to inhibition of the degradation of the above peptides, and short-term studies with doses of alogliptin up to $400 \mathrm{mg}$ /day for 14 days in T2DM subjects have reported no dose-limiting toxicities. ${ }^{131}$

\section{Drug-drug interactions}

Alogliptin has not been associated with any significant drugdrug or drug-food interactions. Alogliptin may be taken without regard to meals. ${ }^{139}$ Alogliptin has been studied in combination with pioglitazone, glyburide, metformin, cimetidine, cyclosporine, and digoxin. Pioglitazone increased the AUC of alogliptin by $10 \%$, but this is considered to be of no clinical significance. ${ }^{140}$

\section{Alogliptin-pioglitazone combination therapy}

The combination of two antihyperglycemic agents with different, but complementary, mechanisms of action, a low risk of hypoglycemia, and easy, once-daily dosing is a logical step in the treatment of T2DM. Several studies or abstracts have examined this combination.

Pratley et $\mathrm{al}^{141}$ reported an international double-blind, randomized, placebo-controlled study in T2DM subjects randomized to alogliptin $12.5 \mathrm{mg} /$ day $(\mathrm{n}=197)$, alogliptin $25 \mathrm{mg} /$ day $(\mathrm{n}=199)$, or placebo $(\mathrm{n}=97)$. Subjects were on a TZD at baseline and, during a four-week run-in period, were stabilized on pioglitazone at $35 \mathrm{mg}$ /day on average. If subjects were on pioglitazone, the current daily dose was continued; if on rosiglitazone, the subject was switched to the equivalent dose of pioglitazone, at $30 \mathrm{mg}$ or $45 \mathrm{mg}$ daily, and subjects were continued on metformin or sulfonylurea if their dose was stable for at least one month. At baseline, subjects were well matched with respect to mean age (55 years), ethnicity (white, 74\%), duration of diabetes (7.6 years), body mass index (BMI, $\left.32.8 \mathrm{~kg} / \mathrm{m}^{2}\right)$, and baseline $\mathrm{HbA}_{1 \mathrm{c}}(8.0 \%)$. Concomitant therapy was metformin in 55\% (mean dose $1688 \mathrm{mg}$ /day), sulfonylurea in 20\% (mean dose $37 \mathrm{mg} /$ day), and no concomitant therapy $(25 \%)$ at baseline. After 26 weeks, $\mathrm{HbA}_{1 \mathrm{c}}$ and FPG were significantly reduced from baseline versus placebo (alogliptin $12.5 \mathrm{mg} /$ day: $-20 \mathrm{mg} / \mathrm{dL}$ and $-0.66 \%$; alogliptin $25 \mathrm{mg} /$ day: $-0.8 \%$ and $-20 \mathrm{mg} / \mathrm{dL}$; placebo: $-0.19 \%$ and $-6 \mathrm{mg} / \mathrm{dL})$. Subjects treated with either dose of alogliptin, $12.5 \mathrm{mg}(44.2 \%)$ or $25 \mathrm{mg}$ (49.2\%), were more likely than placebo (34\%) to reach the $\mathrm{HbA}_{1 \mathrm{c}}$ goal of $\leq 7.0 \%, P=0.01)$. The number of subjects achieving a $\mathrm{HbA}_{1 \mathrm{c}}$ reduction $\geq 1.0 \%$ was two-fold greater in the alogliptin $12.5 \mathrm{mg} /$ day group and three-fold higher in the alogliptin $25 \mathrm{mg} /$ day group compared with placebo, and significantly fewer alogliptin subjects needed hyperglycemic rescue treatment (Figure 9). Average weight gain was approximately $1 \mathrm{~kg}$ with no significant differences between any of the three groups. Both doses of alogliptin were well tolerated and similar numbers of subjects $(3 \%-4 \%)$ compared with placebo discontinued therapy due to adverse events. The total number of adverse events was similar (18\%-19\%) between alogliptin and placebo groups. Adverse reactions possibly related to alogliptin included one subject each with palpitations, CHF, road traffic accident, hypokalemia, serum sickness, and sudden death (no autopsy was performed). Hypoglycemia rates were dependent on baseline therapy. Importantly, in subjects taking the sulfonylurea-pioglitazone combination, rates of hypoglycemia were about $20 \%$ versus about $3 \%$ in subjects taking pioglitazone--metformin. This substantiates our previous observations that combination therapy with medications, such as metformin, pioglitazone, and GLP-1-based incretinomimetic agents, are associated with a very low risk of adverse effects and hypoglycemia. This 
will increase the likelihood of patients continuing therapy and achieving glycemic goals.

\section{Alogliptin-pioglitazone combination therapy}

Combination therapy with alogliptin-pioglitazone has been examined in conjunction with various background therapies (Table 1). In a randomized, double-blind, placebo-controlled, 26-week study, DeFronzo et al ${ }^{142}$ investigated the combination of alogliptin-pioglitazone in subjects inadequately controlled on metformin. Arms of the study included placebo, alogliptin $12.5 \mathrm{mg}$ /day and $25 \mathrm{mg} /$ day, pioglitazone $15 \mathrm{mg} /$ day, $30 \mathrm{mg} /$ day, and $45 \mathrm{mg} /$ day, and alogliptin $12.5 \mathrm{mg} /$ day or $25 \mathrm{mg}$ /day combined with pioglitazone $15 \mathrm{mg} /$ day, $30 \mathrm{mg} /$ day, or $45 \mathrm{mg} /$ day. For analysis, the authors pooled all doses of pioglitazone, alogliptin $12.5 \mathrm{mg}$ /day plus any dose of pioglitazone, and alogliptin $25 \mathrm{mg}$ /day plus any dose of pioglitazone. The mean change in $\mathrm{HbA}_{1 \mathrm{c}}$ from baseline was $-0.89 \%$ in the pioglitazone groups, $-1.43 \%$ in the alogliptin $12.5 \mathrm{mg}$ + pioglitazone groups, and $-1.42 \%$ in the alogliptin $25 \mathrm{mg}+$ pioglitazone groups (both alogliptin doses + pioglitazone were significant at $P<0.001$ versus pioglitazone alone). The mean change in FPG was $-28,-45$, and $-44 \mathrm{mg}$ / $\mathrm{dL}$ for the pioglitazone, alogliptin $12.5 \mathrm{mg}$ + pioglitazone, and alogliptin $25 \mathrm{mg}+$ pioglitazone groups, respectively. ${ }^{143}$ The combination of alogliptin-pioglitazone significantly improved beta cell function measures of the proinsulin to insulin ratio and HOMA-IR versus pioglitazone alone $(-0.087$ and $18.2 ;-0.076$ and $22.2 ;-0.027$ and 5.1 , respectively). HOMA-IR improved in all groups, but did not reach statistical significance between groups (Table 1). ${ }^{143}$

In a randomized, double-blind, 26-week study, 655 subjects (age 53 years, duration of diabetes 3.2 years, $\mathrm{HbA}_{1 \mathrm{c}} 8.8 \%$, FPG $191 \mathrm{mg} / \mathrm{dL}, \mathrm{BMI} 21 \mathrm{~kg} / \mathrm{m}^{2}$ ) inadequately controlled on diet and exercise were given an alogliptinpioglitazone combination (alogliptin $12.5 \mathrm{mg}+$ pioglitazone $30 \mathrm{mg}$ or alogliptin $25 \mathrm{mg}$ + pioglitazone $30 \mathrm{mg}$ daily) or monotherapy with alogliptin $25 \mathrm{mg} /$ day or pioglitazone $30 \mathrm{mg}$ /day. At 26 weeks, the decrements in $\mathrm{HbA}_{1 \mathrm{c}}$ and FPG in the four groups were $1.7 \%$ and $50 \mathrm{mg} / \mathrm{dL}, 1.56 \%$ and $48 \mathrm{mg} / \mathrm{dL}, 1.1 \%$ and $28 \mathrm{mg} / \mathrm{dL}, 0.96 \%$ and $26 \mathrm{mg} / \mathrm{dL}$ for the alogliptin $25 \mathrm{mg}+$ pioglitazone $30 \mathrm{mg}$, alogliptin $12.5 \mathrm{mg}+$ pioglitazone $30 \mathrm{mg}$, pioglitazone $30 \mathrm{mg} /$ day, and alogliptin $25 \mathrm{mg}$ /day groups, respectively. $\mathrm{HbA}_{1 \mathrm{c}}$ reduction was superior with both combination therapies compared with alogliptin alone $(P<0.001)$ and alogliptin $25 \mathrm{mg}+$ pioglitazone $30 \mathrm{mg}$ was superior to pioglitazone monotherapy $(P<0.001)$. Weight changes were $+3.1,+2.5,+2.2$, and $-0.3 .0 \mathrm{~kg}$ in the four groups, respectively. Hypoglycemia was $\leq 3.0 \%$ in all groups. ${ }^{144}$ Combination alogliptin-pioglitazone therapy improved beta cell function compared with alogliptin alone. Proinsulin to insulin ratio ( $30 \%$ versus $14 \%, P=0.006)$, HOMA- $\beta$ (67\% versus $16 \%, P=0.018)$, and HOMA-IR (46\% versus $16 \%, P<0.001$ ) improved more in the alogliptin $25 \mathrm{mg}$ + pioglitazone $30 \mathrm{mg}$ group than in the alogliptin $25 \mathrm{mg}$ /day alone groups. In addition, the increases in adiponectin and decrease in high-sensitivity CRP were significantly improved with alogliptin $25 \mathrm{mg}+$ pioglitazone $30 \mathrm{mg}$ versus alogliptin $25 \mathrm{mg} /$ day monotherapy ${ }^{145}$ (Table 1).

\section{Conclusion}

Type 2 diabetes is characterized by at least eight pathophysiologic abnormalities (Figure 10).${ }^{17}$ The combination of alogliptin plus pioglitazone improves at least six of these pathophysiologic disturbances, including improved insulin resistance in skeletal muscle ( $\rightarrow \uparrow$ muscle glucose uptake), liver ( $\rightarrow \downarrow$ hepatic glucose production), and adipocytes $(\downarrow$ lipolysis $\rightarrow \downarrow$ plasma FFA), increased incretin effect, enhanced insulin secretion, and decreased glucagon secretion (Figure 10). Insulin resistance is an early manifestation in individuals with IGT and T2DM and increases beta cell stress, contributing to beta cell failure and the eventual development of overt T2DM. Insulin resistance can be improved with insulin-sensitizing drugs. Metformin is a weak peripheral (muscle) insulin sensitizer, but improves hepatic insulin sensitivity and reduces HGP. TZDs, such as pioglitazone, are potent insulin sensitizers in both peripheral tissues (muscle and adipocytes) and liver. Beta cell function is markedly impaired in T2DM, and alpha cell secretion of glucagon is increased. GLP-1 is deficient in T2DM, and beta cell responsiveness to GLP-1 is markedly impaired. On average, the incretin effect in T2DM individuals is reduced by approximately half compared with nondiabetic patients. GLP-1 increases insulin secretion, decreases glucagon, slows gastric emptying, and results in satiety and weight loss. The two methods of replacing GLP-1 include GLP-1 receptor agonists, which are effective in mimicking all the actions of GLP-1. Blocking the endogenous enzyme, DPP-4, which degrades active GLP-1, which is also effective in elevating to normal the reduced circulating GLP-1 levels that are present in T2DM. DPP-4 inhibitors augment beta cell function and simultaneously reduce elevated plasma glucagon levels in T2DM patients.

Alogliptin has been studied as monotherapy and in combination with metformin, sulfonylureas, TZDs, and insulin. Alogliptin significantly improves $\mathrm{HbA}_{1 \mathrm{c}}$, is weight 


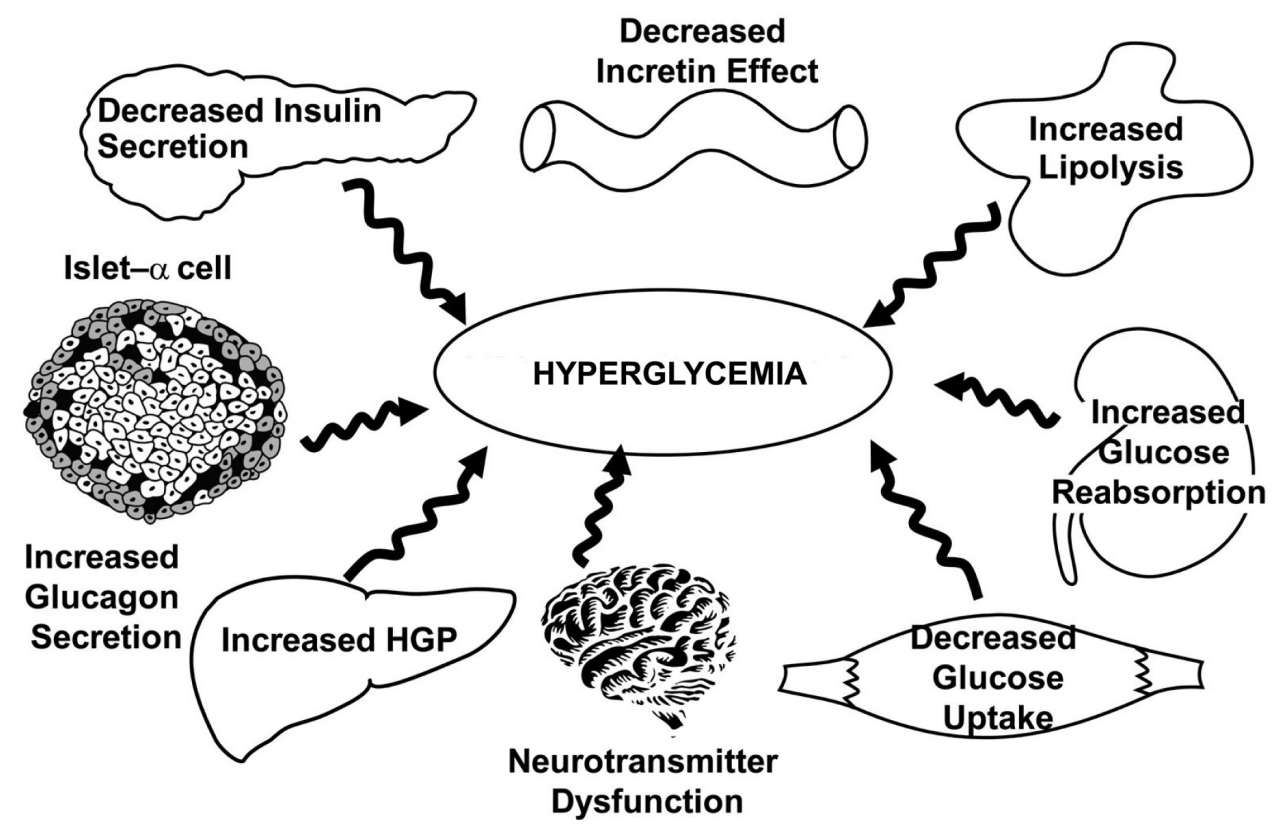

Figure 10 The ominous octet: pathophysiologic abnormalities in type 2 diabetes mellitus. ${ }^{7}$

neutral, does not cause hypoglycemia unless combined with an insulin secretagogue or insulin, has few associated side effects, and very few people discontinue the medication due to intolerance. Pruritic reactions appear to be slightly higher with alogliptin versus placebo, but no significant increase in skin lesions has been observed. The alogliptin-pioglitazone combination reverses multiple metabolic defects in T2DM (Figure 10). With regard to the beta cell defect, pioglitazone decreases lipotoxicity and exerts direct effects via the peroxisome-proliferator activated receptor-gamma to augment insulin secretion, while alogliptin improves islet function by increasing insulin secretion and lowering glucagon secretion in response to elevated plasma glucose levels. Alogliptin-pioglitazone gives an additive effect to improve $\mathrm{HbA}_{1 \mathrm{c}}$ and reduce $\mathrm{FPG}$, while the risk of hypoglycemia is similar to that with placebo. Alogliptin is weight neutral, whereas alogliptin-pioglitazone combination therapy is usually associated with a $1-3 \mathrm{~kg}$ of weight gain during the first year of treatment. Combination therapy also reduces high-sensitivity CRP and increases adiponectin levels. CHICAGO, PERISCOPE, and PROActive demonstrate that pioglitazone has positive effects on vascular function and reduces cardiovascular events. The combination of pioglitazone-alogliptin addresses insulin resistance and islet cell dysfunction in T2DM patients in a once-daily medication that is well tolerated, effectively lowers $\mathrm{HbA}_{1 \mathrm{c}}$, and has a very low risk of hypoglycemia. In summary, alogliptin-pioglitazone combination therapy can reverse known several pathophysiologic processes in T2DM and is clinically effective.

\section{Disclosure}

The authors report no conflict of interest in this work.

\section{References}

1. Statistics Clearinghouse, NIH/NIDDK. Available from: diabetes.niddk. nih.gov. Accseesed on Apr 14, 2010.

2. UK Prospective Diabetes Study (UKPDS) Group. Intensive blood-glucose control with sulphonylureas or insulin compared with conventional treatment and risk of complications in patients with Type 2 diabetes (UKPDS 33). Lancet. 1998;352:837-853.

3. Stratton IM, Adler AI, Neil HAW, et al. Association of glycaemia with macrovascular and microvascular complications of Type 2 diabetes (UKPDS 35): Prospective observational study. BMJ. 2000;321: 405-412.

4. UK Prospective Diabetes Study (UKPDS) Group. Effect of intensive blood-glucose control with metformin on complications in overweight patients with Type 2 diabetes (UKPDS 34). Lancet. 1998;352: 854-865.

5. Kahn SE, Haffner SM, Heise MA, et al. Glycemic durability of rosiglitazone, metformin, or glyburide monotherapy. N Engl J Med. 2006;355: 2427-2443.

6. Brown JB, Nichols GA, Perry A. The burden of treatment failure in Type 2 diabetes. Diabetes Care. 2004;27:1535-1340.

7. DeFronzo RA. From the triumvirate to the ominous octet: A new paradigm for the treatment of Type 2 diabetes mellitus. Diabetes. 2009:58:773-795.

8. Bullock BP, Heller RS, Habener JF. Tissue distribution of messenger ribonucleic acid encoding the rat glucagon-like peptide-1 receptor. Endocrinology. 1996;137:2968-2978.

9. Brubaker PL, Drucker DJ. Structure-function of the glucagon receptor family of G protein-coupled receptors: The glucagon, GIP, GLP-1, and GLP-2 receptors. Receptor Channels. 2002;8:179-188.

10. Gedulin B, Lawler R, Jodka C, Young A. Amylin inhibits pentagastrin-stimulated gastric acid secretion: Comparison with glucagon-like peptide-1 and exendin-4. Diabetes. 1997;46: Abstr 188.

11. DeFronzo RA, Okerson T, Viswanathan P, et al. Effects of exenatide versus sitagliptin on postprandial glucose, insulin and glucagon secretion, gastric emptying, and caloric intake: A randomized, cross-over study. Curr Med Res Opin. 2008;24:2943-2952. 
12. Saydah SH, Fradkin J, Cowie CC. Poor control of risk factors for vascular disease among adults with previously diagnosed diabetes. JAMA. 2004;291:335-342.

13. Koro CE, Bowlin SJ, Bourgeois N, Fedder DO. Glycemic control from 1988 to 2000 among US adults diagnosed with Type 2 diabetes: A preliminary report. Diabetes Care. 2004;27:17-20.

14. Cheung BMY, Ong KL, Cherney SS, et al. Diabetes prevalence and therapeutic target achievement in the United States, 1999-2006. Am J Med. 2009;122:443-453.

15. DeFronzo RA. Pathogenesis of Type 2 diabetes: Metabolic and molecular implications for identifying diabetes genes. Diabetes Reviews. 1997;5;177-269.

16. DeFronzo RA. Lilly lecture. The triumvirate: Beta-cell, muscle, liver. A collusion responsible for NIDDM. Diabetes. 1998;37:667-687.

17. DeFronzo RA. Pathogenesis of Type 2 diabetes mellitus. Med Clin N Am. 2004;88:787-835.

18. Kahn SE. Clinical Review 135. The importance of beta-cell failure in the development and progression of Type 2 diabetes. J Clin Endocrinol Metab. 2001;86:4047-4058.

19. Bergman RN, Finegood DT, Kahn SE. The evolution of beta-cell dysfunction and insulin resistance in Type 2 diabetes. Eur J Clin Invest. 2002;32:35-45.

20. Reaven GM, Hollenbeck C, Jeng C-Y, Wu MS, Chen Y-DI. Measurement of plasma glucose, free fatty acid, lactate, and insulin for 24 hours in patients with NIDDM. Diabetes. 1998;37:1020-1104.

21. McGarry JD. Banting Lecture 2001: Dysregulation of fatty acid metabolism in the etiology of Type 2 diabetes. Diabetes. 2002;51:7-18.

22. Belfort R, Harrison SA, Brown K, et al. A placebo-controlled trial of pioglitazone in subjects with nonalcoholic steatohepatitis. $N$ Engl J Med. 2006:355:2297-2307.

23. Boden $\mathrm{G}$. Role of fatty acids in the pathogenesis of insulin resistance and NIDDM. Diabetes. 1997;46:3-10.

24. Belfort R, Mandarino L, Kashyap S, et al. Dose-response effect of elevated plasma free fatty acid on insulin signaling. Diabetes. 2005;54: 1640-1648.

25. Rossetti L, Giaccari A, DeFronzo RA. Glucose toxicity. Diabetes Care. 1990;13:610-630.

26. Bays H, Mandarino L, DeFronzo RA. Role of the adipocyte, free fatty acids, and ectopic fat in pathogenesis of Type 2 diabetes mellitus: Peroxisomal proliferator-activated receptor agonists provide a rational therapeutic approach. J Clin Endocrinol Metab. 2004;89: 463-478.

27. Rossetti L, Shulman GI, Zawalich W, DeFronzo RA. Effect of chronic hyperglycemia on in vivo insulin secretion in partially pancreatectomized rats. J Clin Invest. 1987;80:1037-1044.

28. Kashyap S, Belfort R, Gastaldelli A, et al. A sustained increase in plasma free fatty acids impairs insulin secretion in nondiabetic subjects genetically predisposed to develop Type 2 diabetes. Diabetes. 2003;52:2461-2474.

29. Gastaldelli A, Ferrannini E, Miyazaki Y, Matsuda M, DeFronzo RA. Beta-cell dysfunction and glucose intolerance: Results from the San Antonio Metabolism (SAM) study. Diabetologia. 2004;41: 31-39.

30. Diabetes Prevention Research Group: Reduction in the evidence of Type 2 diabetes with life-style intervention or metformin. $N$ Engl J Med. 2002;346:393-403.

31. Buchanan TA, Xiang AH, Peters RK, et al. Preservation of pancreatic beta-cell function and prevention of Type 2 diabetes by pharmacological treatment of insulin resistance in high-risk Hispanic women. Diabetes. 2002;51:2796-2803.

32. Buchanan TA, Xiang AH, Kjos SL, et al. Diabetes rates and B-cell function in the pioglitazone and prevention of diabetes (PIPOD) study. Diabetes. 2005;54 Suppl 1:A39.

33. DeFronzo RA, Banerji M, Bray GA, et al. Actos NOW for the prevention of diabetes (ACT NOW) study. BMC Endocr Disord. 2009;9:17-25.
34. Wang Q, Brubaker PL. Glucagon-like peptide-1 treatment delays the onset of diabetes in 8 week old db/db mice. Diabetologia. 2002;45: $1263-1273$.

35. Gedulin BR, Nikoulina SE, Smith PA, et al. Exenatide (exendin-4) improves insulin sensitivity and beta-cell mass in insulin resistant obese $\mathrm{fa} / \mathrm{fa}$ Zucker rats independent of glycemia and body weight. Endocrinology. 2005;146:2069-2076.

36. Ahren B, Pacini G, Foley JE, Schweizer A. Improved meal-related beta-cell function and insulin sensitivity by the dipeptidyl peptidase-IV inhibitor vildagliptin in metformin-treated patients with Type 2 diabetes over 1 year. Diabetes Care. 2005;28:1936-1940.

37.Xu L, Man CD, Charbonnel B, et al. Effect of sitagliptin, a dipeptidylpeptidase 4 inhibitor, on beta-cell function in patients with Type 2 diabetes, a model-based approach. Diabetes Obes Metab. 2008;10: 1212-1220.

38. Muller WA, Faloona GR, Aguilar-Parada E, Unger RH. Abnormal alpha-cell function in diabetes: Response to carbohydrate and protein ingestion. N Engl J Med. 1970;283:109-115.

39. Unger RH, Aguilar-Parada E, Muller WA, Eisentraut AM. Studies of pancreatic alpha cell function in normal and diabetic subjects. J Clin Invest. 1970;49:837-848.

40. Aguilar-Parada E, Eisentraut AM, Unger RH. Pancreatic glucagon secretion in normal and diabetic subjects. Am J Med Sci. 1969;257: 415-419.

41. Matsuda M, DeFronzo RA, Consoli A, Bressler P, Del Prato S. Doseresponse curve relation plasma glucagon to hepatic glucose production and glucose disposal in Type 2 diabetes mellitus. Metabolism. 2002; 51:1111-1119.

42. Schwartz JG, Green GM, Guan D, McMahan CA, Phillips WT. Rapid gastric emptying of a solid pancake meal in Type II diabetic patients. Diabetes Care. 1996;19:468-471.

43. Miyazaki Y, Mahankali A, Matsuda M, et al. Effect of pioglitazone on abdominal fat distribution and insulin sensitivity in Type 2 diabetic patients. J Clin Endocrinol Metab. 2002;87:2784-2791.

44. Miyazaki Y, DeFronzo RA. Rosiglitazone and pioglitazone similarly improve insulin sensitivity and secretion, glucose tolerance and adipocytokines in Type 2 diabetic patients. Diabetes Obes Metab. 2008;10: 1204-1211.

45. Matthews DR, Charbonnel BH, Hanefeld M, Brunetti P, Schernthaner G. Long-term therapy with addition of pioglitazone to metformin compared with the addition of gliclazide to metformin in patients with Type 2 diabetes: A randomized, comparative study. Diabetes Metab Res Rev. 2005;21:167-174.

46. Gastaldelli A, Ferrannini E, Miyazaki Y, Matsuda M, Mari A, DeFronzo RA. Thiazolidinediones improve beta-cell function in Type 2 diabetic patients. Am J Physiol Endocrinol Metab. 2007;292: E871-E883.

47. Hanefeld M, Marx N, Pfutzner A, et al. Anti-inflammatory effects of pioglitazone and/or simvastatin in high cardiovascular-risk patients with elevated high sensitivity c-reactive protein: The PIOSTAT study. J Am Coll Cardiol. 2007;49:290-297.

48. Fernandez M, Triplitt C, Wajcberg E, et al. Addition of pioglitazone and ramipril to intensive insulin therapy in Type 2 diabetes patients improves vascular dysfunction by different mechanisms. Diabetes Care. 2008;31:121-127.

49. Wajcberg E, Sriwijitkamol A, Musi N, DeFronzo RA, Cersosimo E. Relationship between vascular reactivity and lipids in Mexican-Americans with Type 2 diabetes treated with pioglitazone. J Clin Endocrinol Metab. 2007;92:1256-1262.

50. Goldberg RB, Kendall DM, Deeg MA, et al. A comparison of lipid and glycemic effects of pioglitazone and rosiglitazone in patients with Type 2 diabetes and dyslipidemia. Diabetes Care. 2005;28:1547-1554.

51. Lloyd-Jones DM, Bloch KD. The vascular biology of nitric oxide and its role in atherogenesis. Annu Rev Med. 1996;47:365-375.

52. de Caterina R, Libby P, Peng HB, et al. Nitric oxide decreases cytokineinduced endothelial activation: Nitric oxide selectively reduces endothelial expression of adhesion molecules and proinflammatory cytokines. J Clin Invest. 1995;96:60-68. 
53. Defronzo RA. Insulin resistance, lipotoxicity, Type 2 diabetes and atherosclerosis: The missing links. The Claude Bernard Lecture 2009. Diabetologia. 2010;53:1270-1287.

54. Bajaj M, Suraamornkul S, Hardies LJ, Pratipanawatr T, DeFronzo RA. Plasma resistin concentration, hepatic fat content, and hepatic and peripheral insulin resistance in pioglitazone-treated Type 2 diabetic patients. Int J Obes. 2004;28:783-789.

55. Miyazaki Y, Mahankali A, Matsuda M, et al. Improved glycemic control and enhanced insulin sensitivity in liver and muscle in Type 2 diabetic subjects treated with pioglitazone. Diabetes Care. 2001;24: $710-719$.

56. Gastaldelli A, Miyazaki Y, Mahankali A, et al. The effect of pioglitazone on the liver. Diabetes Care. 2006;29:2275-2281.

57. Gastaldelli A, Ferrannini E, Miyazaki Y, Matsuda M, Mari A, DeFronzo RA. Thiazolidinediones improve beta-cell function in Type 2 diabetes patients. Am J Physiol Endocrinol Metab. 2007;292: E871-E883.

58. Chiquette E, Ramirez G, DeFronzo R. A meta-analysis comparing the effect of thiazolidinediones on cardiovascular risk factors. Arch Intern Med. 2004;164:2097-2104.

59. Nissen SE, Wolski K. Effect of rosiglitazone on the risk of myocardial infarction and death from cardiovascular causes. $N$ Engl J Med. 2007;356:2457-2471

60. Singh S, Loke UK, Furberg CD. Long-term risk of cardiovascular events with rosiglitazone. JAMA. 2007;298:1189-1195.

61. Miyazaki Y, Matsuda M, Defronzo RA. Dose-response effect of pioglitazone on insulin sensitivity and insulin secretionin Type 2 diabetes. Diabetes Care. 2002;25:517-523.

62. Klonoff DC, Buse JB, Nielsen LL, et al. Exenatide effects on diabetes, obesity, cardiovascular risk factors and hepatic biomarkers in patients with Type 2 diabetes treated for at least 3 years. Curr Med Res Opin. 2008;24:275-286.

63. The Dream (Diabetes REduction Assessment with ramipril and rosiglitazone Medication) Trial Investigators. Effect of rosiglitazone on the frequency of diabetes in patients with impaired glucose tolerance or impaired fasting glucose: A randomized controlled trial. Lancet. 2006;368:1096-1105

64. Bunck MC, Diamont M, Corner A, et al. One-year treatment with exenatide improves $\beta$-cell function, compared with insulin glargine, in metformin-treated Type 2 diabetic patients: A randomized, controlled trial. Diabetes Care. 2009;32:762-768.

65. DeFronzo RA, Banerji MA, Bray GA, et al; for the ACT NOW Study Group. Determinants of glucose tolerance in impaired glucose tolerance at baseline in the Actos Now for Prevention of Diabetes (ACT NOW). Diabetologia. 2010;53:435-445.

66. Abdul-Ghani MA, Jenkinson CP, Richardson DK, Tripathy D, DeFronzo RA. Insulin secretion and action in subjects with impaired fasting glucose and impaired glucose tolerance: Results from the Veterans Administration Genetic Epidemiology Study. Diabetes. 2006;55:1430-1435.

67. Nissen SE, Nicholls SJ, Wolski K; PERISCOPE Investigators. Comparison of pioglitazone vs glimepiride on progression of coronary atherosclerosis in patients with Type 2 diabetes: The PERISCOPE randomized controlled trial. JAMA. 2008;299:1561-1573.

68. Mazzone T, Meyer PM, Feinstein SB, et al. Effect of pioglitazone compared with glimepiride on carotid intima-media thickness in Type 2 diabetes: A randomized trial. JAMA. 2006;296:2572-2581.

69. Charbonnel B, Schernthaner G, Brunetti P, et al. Long-term efficacy and tolerability of add-on pioglitazone therapy to failing monotherapy compared with addition of gliclazide or metformin in patients with Type 2 diabetes. Diabetologia. 2005;48:1093-1104.

70. Hanefeld M, Pfutzner A, Forst T, Lubben G. Glycemic control and treatment failure with pioglitazone versus glibenclamide in Type 2 diabetes mellitus: A 42-month, open-label, observational, primary care study. Curr Med Res Opin. 2006;22:1211-1215.

71. Tan MH, Baksi A, et al; GLAL Study Group. Comparison of pioglitazone and gliclazide in sustaining glycemic control over 2 years in patients with Type 2 diabetes. Diabetes Care. 2005;28:544-550.
72. Rosenstock J, Goldstein BJ, Vinik A; RESULT Study Group. Effect of early addition of rosiglitazone to sulphonylurea therapy in older Type 2 diabetes patients (60 years): The Rosiglitazone Early vs SULphonylurea Titration (RESULT) study. Diab Obes Metab. 2006;8:49-57.

73. Home PD, Jones NP, Pocock SJ, et al. RECORD Study Group. Rosiglitazone RECORD study: Glucose control outcomes at 18 months. Diabet Med. 2007;24:626-634.

74. Miyazaki Y, DeFronzo RA. Rosiglitazone and pioglitazone similarly improve insulin sensitivity and secretion, glucose tolerance and adipocytokines in Type 2 diabetic patients. Diabetes Obes Metab. 2008;10: 1204-1211.

75. Rosmarakis ES, Falagas ME. Effect of thiazolidinedione therapy on restenosis after coronary stent implantation: A meta-analysis of randomized controlled trials. Am Heart J. 2007;154:144-150.

76. Lincoff AM, Wolski K, Nicholls SJ, Nissen SE. Pioglitazone and risk of cardiovascular events in patients with Type 2 diabetes mellitus: A meta-analysis of randomized trials. JAMA. 2007;12;298:1180-1188.

77. Dormandy JA, Charbonnel B, Eckland DJA, et al. Secondary prevention of macrovascular events in patients with Type 2 diabetes in the proactive study (PROspective pioglitAzone Clincal Trial In macroVascular Events): A randomized controlled trial. Lancet. 2005;366:1279-1289.

78. Miyazaki Y, Glass L, Triplitt C, et al. Abdominal fat distribution and peripheral and hepatic insulin resistance in Type 2 diabetes mellitus. Am J Physiol Endocrinol Metab. 2002;46:E1135- 1481, E1143.

79. Petersen KF, Dufour S, Shulman GI. Decreased insulin-stimulated ATP synthesis and phosphate transport in muscle of insulinresistant offspring of Type 2 diabetic parents. PLoS Medicine. 2005;2:879-884.

80. Nesto RW, Bell D, Bonow RO, et al. Thiazolidinedione use, fluid retention, and congestive heart failure: A consensus statement from the American Heart Association and the American Diabetes Association: Oct 7, 2003. Circulation. 2003;108:2941-2948.

81. Kaul S, Bolger A, Herrington D, Giugliano R, Eckel R. Thiazolidinedione drugs and cardiovascular risks: A science advisory from the American Heart Association and American College of Cardiology Foundation. Circulation. 2010;121:1868-1877.

82. Masoudi FA, Inzucchi SE, Wang Y, Havranek EP, Foody JM, Krumholz HM. Thiazolidinediones, metformin, and outcomes in older patients with diabetes and heart failure; an observational study. Circulation. 2005;111:583-590.

83. Puschett JB. Pharmacological classification and renal actions of diuretics. Cardiology. 1994;84 Suppl 2:4-13.

84. Karalliedde J, Buckingham R, Starkie M, et al. Effect of various diuretic treatments on rosiglitazone-induced fluid retention. J Am Soc Nephrol. 2006;17:3482-3490.

85. Valentine WJ, Bottomley JM, Palmer AJ, et al; PROactive Study Group. PROactive 06: Cost-effectiveness of pioglitazone in Type 2 diabetes in the UK. Diabet Med. 2007;24:982-1002.

86. Nauck M, Stockmann F, Ebert R, Creutzfeldt W. Reduced incretin effect in Type 2 (non-insulin-dependent) diabetes. Diabetologia. 1986;29:46-52.

87. Vilsboll T, Holst JJ. Incretins, insulin secretion and Type 2 diabetes mellitus. Diabetologia. 2004;47:357-366.

88. Meier JJ, Nauck MA, Schmidt WE, Gallwitz B. Gastric inhibitory polypeptide: The neglected incretin revisited. Regul Pept. 2002;107: $1-13$.

89. Toft-Nielsen MB, Damholt MB, Madsbad S, et al. Determinants of the impaired secretion of glucagon-like peptide- 1 in Type 2 diabetic patients. J Clin Endocrinol Metab. 2001;86:3717-3723.

90. Drucker DJ. Glucagon-like peptides. Diabetes. 1998;47:159-169.

91. Jones IR, Owens DR, Luzio S, Williams S, Hayes TM. The glucose dependent insulinotropic polypeptide response to oral glucose and mixed meals is increased in patients with Type 2 (noninsulin-dependent) diabetes mellitus. Diabetologia. 1989;32: 668-677. 
92. Nauck MA, Heimesaat MM, Orskov C, et al. Preserved incretin activity of glucagon-like peptide-1 [7-36 amide] but not of synthetic human gastric inhibitory polypeptide in patients with Type-2 diabetes mellitus. J Clin Invest. 1993;91:301-307.

93. Drucker DJ, Nauck MA. The incretin system: Glucagon-like peptide-1 receptor agonists and dipeptidyl peptidase-4 inhibitors in Type 2 diabetes. Lancet. 2006;368:1696-1705.

94. Deacon CF. Incretin-based treatment of Type 2 diabetes: Glucagonlike peptide-1 receptor agonists and dipeptidyl peptidase-4 inhibitors Diabetes Obes Metab. 2007;9 Suppl 1:23-31.

95. Ferrannini E, Bjorkman O, Reichard GA, Pilo A, Olson M. The disposal of an oral glucose load in healthy subjects. A quantitative study. Diabetes. 1985;34:580-588.

96. Ahren B. Gut peptides and Type 2 diabetes mellitus treatment. Curr Diab Rep. 2003;3:365-372.

97. Ahren B. Insulinotropic action of truncated glucagon-like peptide-1 in mice. Acta Physiol Scand. 1995;153:205-206.

98. Drucker DJ, Philippe J, Mojsov S, Chick WL, Habener JF. Glucagonlike peptide I stimulates insulin gene expression and increases cyclic AMP levels in a rat islet cell line. Proc Natl Acad Sci U S A. 1987; $84: 3434$.

99. Kashima Y, Miki T, Shibasaki T, et al. Critical role of cAMP-GEFII Rim2 complex in incretin-potentiated insulin secretion. J Biol Chem. 2001;276:46046-46053.

100. Fehmann HC, Goke R, Goke B. Glucagon-like peptide-1(7-37)/ (7-36)amide is a new incretin. Mol Cell Endocrinol. 1992;85: C39-C44.

101. Wang Y, Egan JM, Raygada M, Nadiv O, Roth J, MontroseRafizadeh C. Glucagon-like peptide-1 affects gene transcription and messenger ribonucleic acid stability of components of the insulin secretory system in RIN 1046-38 cells. Endocrinology. 1995;136: 4910-4917.

102. Fehmann HC, Habener JF. Insulinotropic hormone glucagon-like peptideI(7-37) stimulation of proinsulin gene expression and proinsulin biosynthesis in insulinoma beta TC-1 cells. Endocrinology. 1992;130:159-166.

103. Fehmann HC, Habener JF. Galanin inhibits proinsulin gene expression stimulated by the insulinotropic hormone glucagon-like peptide-I(7-37) in mouse insulinoma beta TC-1 cells. Endocrinology. 1992;130:2890-2896.

104. Drucker DJ. Glucagon-like peptides: Regulators of cell proliferation, differentiation, and apoptosis. Mol Endocrinol. 2003; $17: 161-171$.

105. Muller WA, Faloona GR, Aguilar-Parada E, Unger RH. Abnormal alpha-cell function in diabetes: Response to carbohydrate and protein ingestion. $N$ Engl J Med. 1970;283:109-115.

106. Unger RH, Aguilar-Parada E, Muller WA, Eisentraut AM. Studies of pancreatic alpha cell function in normal and diabetic subjects. J Clin Invest. 1970;49:837-848.

107. Aguilar-Parada E, EisentrautAM, Unger RH. Pancreatic glucagon secretion in normal and diabetic subjects. Am J Med Sci. 1969;257: 415-419.

108. Larsson H, Berglund G, Ahren B. Glucose modulation of insulin and glucagon secretion is altered in impaired glucose tolerance. J Clin Endocrinol Metab. 1995;80:1778-1782.

109. Ahren B, Larsson H. Impaired glucose tolerance (IGT) is associated with reduced insulin-induced suppression of glucagon concentrations. Diabetologia. 2001;44:1998-2003.

110. Larsson H, Ahren B. Glucose intolerance is predicted by low insulin secretion and high glucagon secretion: Outcome of a prospective study in postmenopausal Caucasian women. Diabetologia. 2000;43: 194-202.

111. Unger RH. Glucagon physiology and pathophysiology. N Engl J Med. 1971;285:443-449.

112. Heller RS, Kieffer TJ, Habener JF. Insulinotropic glucagon-like peptide I receptor expression in glucagon-producing alpha-cells of the rat endocrine pancreas. Diabetes. 1997;46:785-791.

113. Kolterman OG, Buse JB, Fineman MS, et al. Synthetic exendin-4 (exenatide) significantly reduces postprandial and fasting plasma glucose in subjects with Type 2 diabetes. J Clin Endocrinol Metab. 2003;88:3082-3089.
114. Horowitz M, Dent J, Fraser R, Sun W, Hebbard G. Role and integration of mechanisms controlling gastric emptying. Dig Dis Sci. 1994; 39 Suppl 12:7S-13S.

115. Phillips WT, Schwartz JG, McMahan CA. Rapid gastric emptying of an oral glucose solution in Type 2 diabetic patients. $J$ Nucl Med. 1992;33:1496-1500.

116. Horowitz M, Fraser R. Disordered gastric motor function in diabetes mellitus. Diabetologia. 1994;37:543-551.

117. Schwartz JG, Green GM, Guan D, McMahan CA, Phillips WT. Rapid gastric emptying of a solid pancake meal in Type II diabetic patients. Diabetes Care. 1996;19:468-471.

118. Horowitz M, Edelbroek MA, Wishart JM, Straathof JW. Relationship between oral glucose tolerance and gastric emptying in normal healthy subjects. Diabetologia. 1993;36:857-862.

119. Phillips WT, Schwartz JG, McMahan CA. Rapid gastric emptying of an oral glucose solution in Type 2 diabetic patients. $\mathrm{J} \mathrm{Nucl} \mathrm{Med}$. 1992;33:1496-500.

120. Kolterman OG, Kim DD, Shen L, et al. Pharmacokinetics, pharmacodynamics, and safety of exenatide in patients with Type 2 diabetes mellitus. Am J Health Syst Pharm. 2005;62:173-181.

121. Imeryuz N, Yegen BC, Bozkurt A, Coskun T, VillanuevaPenacarrillo ML, Ulusoy NB. Glucagon-like peptide-1 inhibits gastric emptying via vagal afferent-mediated central mechanisms. Am J Physiol. 1997;273: G920-G927.

122. Orskov C, Poulsen SS, Moller M, Holst JJ. Glucagon-like peptide I receptors in the subfornical organ and the area postrema are accessible to circulating glucagon-like peptide I. Diabetes. 1996;45: 832-835.

123. Tang-Christensen M, Larsen PJ, Goke R, et al. Central administration of GLP-1-(7-36) amide inhibits food and water intake in rats. Am J Physiol. 1996;271:R848-R856.

124. Turton MD, O’Shea D, Gunn I, et al. A role for glucagon-like peptide-1 in the central regulation of feeding. Nature. 1996;379:69-72.

125. Ahren B. Glucagon-like peptide-1 (GLP-1): A gut hormone of potential interest in the treatment of diabetes. Bioessays. 1998;20: 642-651.

126. Verdich C, Flint A, Gutzwiller JP, et al. A meta-analysis of the effect of glucagon-like peptide-1 (7-36) amide on ad libitum energy intake in humans. J Clin Endocrinol Metab. 2001;86:4382-4389.

127. Deacon CF, Nauck MA, Toft-Nielsen M, Pridal L, Willms B, Holst JJ. Both subcutaneously and intravenously administered glucagon-like peptide I are rapidly degraded from the NH2-terminus in Type II diabetic patients and in healthy subjects. Diabetes. 1995;44: 1126-1131.

128. Feng J, Zhang Z, Wallace MB, et al. Discovery of alogliptin: A potent, selective, bioavailable, and efficacious inhibitor of dipeptidyl peptidase IV. J Med Chem. 2007;50:2297-2300.

129. Asakawa T, Moritoh Y, Kataoka O, Suzuki N, Takeuchi K, Odaka H. A novel dipeptidyl peptidase-4 inhibitor, alogliptin (SYR-322), is effective in diabetic rats with sulfonylurea-induced secondary failure. Life Sci. 2009:85:122-126.

130. Moritoh Y, Takeuchi K, Asakawa T, Kataoka, Odaka H. Chronic administration of alogliptin, a novel, potent, and highly selective dipeptidyl peptidase-4 inhibitor, improves glycemic control and beta-cell function in obese diabetic ob/ob mice. Eur J Pharmacol. 2008;588:325-332.

131. Christopher R, Covington P, Davenport M, et al. Pharmacokinetics, pharmacodynamics, and tolerability of single increasing doses of the dipeptidyl peptidase-4 inhibitor alogliptin in health male subjects. Clin Ther. 2008:30:513-527.

132. Onglyza ${ }^{\circledR}$ [package insert]. Princeton, NJ: Bristol-Myers Squibb, 2009.

133. Januvia ${ }^{\circledR}$ [package insert]. Whitehouse Station, NJ: Merck and Company, Inc., 2010

134. Covington P, Christopher R, Davenport M, et al. Pharmacokinetic, pharmacodynamic, and tolerability profiles of the dipeptidyl peptidase-4 inhibitor alogliptin: A randomized, double-blind placebocontrolled multiple-dose study in adult patients with Type 2 diabetes. Clin Ther. 2008;30:499-512. 
135. DeFronzo RA, Fleck PR, Wilson CA, Mekki Q. Efficacy and safety of the dipeptidyl peptidase-4 inhibitor alogliptin in patients with Type 2 diabetes and inadequate glycemic control. Diabetes Care. 2008;31:2315-2317.

136. Pratley RE, Kipnes MS, Fleck PR, Wilson C, Mekki Q. Efficacy and safety of the dipeptidyl peptidase-4 inhibitor alogliptin in patients with Type 2 diabetes inadequately controlled by glyburide monotherapy. Diabetes Obes Metab. 2009;11:167-176.

137. Nauck MA, Ellis GC, Fleck PR, Wilson CA, Mekki Q. Efficacy and safety of adding the dipeptidyl peptidase-4 inhibitor alogliptin to metformin therapy in patients with Type 2 diabetes inadequately controlled with metformin monotherapy: A multicenter, randomized, doubleblind, placebo-controlled study. Int J Clin Pract. 2009;63:46-55.

138. Rosenstock J, Rendell MS, Gross JL, Fleck PR, Wilson CA, Mekki Q. Aloglitpin added to insulin therapy in patients with Type 2 diabetes reduces $\mathrm{HbA}_{1 \mathrm{c}}$ without causing weight gain or increased hypoglycaemia. Diabetes Obes Metab. 2009;11:1145-1152.

139. Karim A, Covington P, Christopher R, et al. Pharmacokinetics of alogliptin when administered with food, metformin, or cimetidine: A two-phase, crossover study in health subjects. Int J Clin Pharmacol Ther. 2010;48:46-58.

140. Karim A, Laurent A, Munsaka M, Wann E, Fleck P, Mekki Q. Coadministration of pioglitazone or glyburide and alogliptin: Pharmacokinetic drug interaction assessment in healthy participants. J Clin Pharmacol. 2009;49:1210-1219.
141. Pratley R, Reusch J, Fleck P, Wilson C, Mekki Q. Efficacy and safety of the dipeptidyl peptidase-4 inhibitor alogliptin added to pioglitazone in patients with Type 2 diabetes: A randomized, double-blind, placebocontrolled study. Curr Med Res Opin. 2009;25:2361-2371.

142. DeFronzo RA, Burant CF, Fleck P, Wilson C, Mekki Q, Pratley RE. Effect of alogliptin combined with pioglitazone in glycemic control in metformin-treated patients with Type 2 diabetes. Diabetes. 2009; 58 Suppl 1:A519, Abstr 2023.

143. Defronzo RA, Burant CF, Fleck P, Wilson C, Mekki Q, Pratley RE. Effect of alogliptin combined with pioglitazone on glycemic control in metformin-treated patients with Type 2 diabetes. Diabetes. 2009; 58 Suppl 1:A519-A520, Abstr 2024.

144. Rosenstock J, Inzucchi S, Seufert J, Fleck P, Wilson C, Mekki Q. Efficacy and safety of alogliptin combined with pioglitazone in patients with Type 2 diabetes inadequately controlled with diet and exercise. Diabetes. 2009;58 Suppl 1:A523, Abstr 2036.

145. Inzucchi SE, Rosenstock J, Seufert J, Fleck P, Wilson C, Mekki Q. Effect of combination therapy with alogliptin and pioglitazone in drug-naïve patients with Type 2 diabetes on b-cell function and insulin resistance. Diabetes. 2009;58 Suppl 1:A520, Abstr 2026.
Vascular Health and Risk Management

\section{Publish your work in this journal}

Vascular Health and Risk Management is an international, peerreviewed journal of therapeutics and risk management, focusing on concise rapid reporting of clinical studies on the processes involved in the maintenance of vascular health; the monitoring, prevention and treatment of vascular disease and its sequelae; and the involvement of

\section{Dovepress}

metabolic disorders, particularly diabetes. This journal is indexed on PubMed Central and MedLine. The manuscript management system is completely online and includes a very quick and fair peer-review system, which is all easy to use. Visit http://www.dovepress.com/ testimonials.php to read real quotes from published authors. 